Portland State University

PDXScholar

Winter 3-11-2015

\title{
The Scales and Shapes of Queer Women's \\ Geographies: Mapping Private, Public and Cyber Spaces in Portland, OR
}

Paola Renata Saldaña
Portland State University

Follow this and additional works at: https://pdxscholar.library.pdx.edu/open_access_etds

Part of the Lesbian, Gay, Bisexual, and Transgender Studies Commons, and the Urban Studies and Planning Commons

Let us know how access to this document benefits you.

\section{Recommended Citation}

Saldaña, Paola Renata, "The Scales and Shapes of Queer Women's Geographies: Mapping Private, Public and Cyber Spaces in Portland, OR" (2015). Dissertations and Theses. Paper 2213.

https://doi.org/10.15760/etd.2210

This Thesis is brought to you for free and open access. It has been accepted for inclusion in Dissertations and Theses by an authorized administrator of PDXScholar. Please contact us if we can make this document more accessible: pdxscholar@pdx.edu. 
The Scales and Shapes of Queer Women's Geographies:

Mapping Private, Public and Cyber Spaces in Portland, OR

by

Paola Renata Saldaña

A thesis submitted in partial fulfillment of the requirements for the degree of

\author{
Master \\ of \\ Urban Studies
}

Thesis Committee:

Sy Adler, Chair

Maura Kelly

Nathan McClintock

Portland State University

2015 


\begin{abstract}
Queer women's relationship to space has been under-theorized due to the difficulties in identifying particular spatial patterns that can describe their presence in urban settings. Most of the research that has focused on queer space has mentioned the difficulty of mapping queer women. The purpose of this research is to identify the ways in which the scarcity of queer women-specific space in Portland, Oregon, has affected the development of a women's community based on a queer identity, the role of intersecting identities such as race and gender identity in these communities and spaces, as well as the implications of queer women's spaces for the development of inclusive spatial frameworks. This research is based on 15 map-making interviews with queer women in the Portland area. During the interviews, participants were asked to draw a map of what they consider to be queer women's space in Portland. The results suggest that queer women occupy an array of places, but lack public queer women-specific spaces. Some of the reasons for the decline in these spaces are changing identities and the political climate, an attempt at inclusion of trans and gender non-conforming people, and racism. In order to better understand queer women's spatial patterns, the scholarship needs frameworks that are inclusive of private, cyber and temporary spaces. Given the lack of scholarship on the relationship between queer women and space, this research contributes to a better understanding of queer women's geographies in a changing political climate.
\end{abstract}




\section{Acknowledgements}

I want to take a moment to acknowledge all of those who have supported me in this particular process, as well as the people who have come before me. Academic work does not occur in a vacuum and I want to particularly recognize other queer and trans writers, Mexican academics and POC intellectuals that have paved the way for me to be here. This work would also not have been possible without the support and patience of all the people in my life. First I would like to thank Dr. Sy Adler, Dr. Maura Kelly and Dr. Nathan McClintock for their input and support through this process. Secondly, I would like to thank my classmates and cohort for helping me through the program and for their continued check-ins and feedback. Third I would like to show my immense appreciation and love to my friends and family who have been patient and loving in the past year. Fourth, I would like to thank my partner, best friend and biggest support, Jenny, for putting up with a year of stress and hard work. Finally, I would like to thank the participants for sharing their experiences and time with me. This work would not have been possible without the support of all the people in my life. 


\section{Table of Contents}

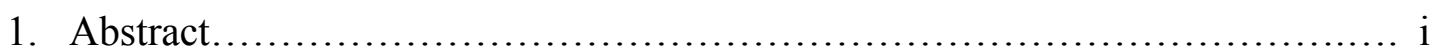

2. Acknowledgements............................................. ii

3. Chapter I: Introduction and Background............................... 1

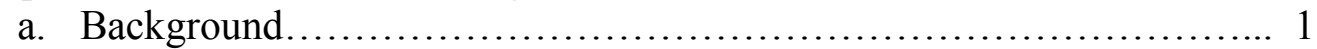

b. Research........................................................... 3

c. Frameworks................................................. 6

4. Chapter II: Queer Women's Space in Portland, OR....................... 12

a. Introduction...................................................... 12

b. Literature on Queer Women's Spaces and Queer Communities.......... 15

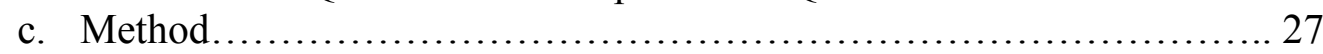

d. Results and Discussion......................................... 33

e. Conclusion..................................................... 70

5. Chapter III: Spatial Frameworks and Queer Mapping.........................78

a. Introduction................................................. 78

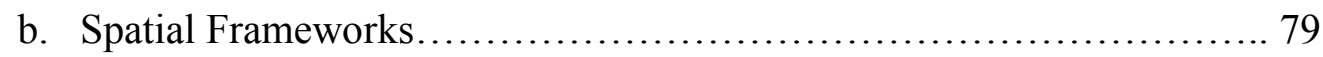

c. Place and Queer Women Spaces....................................... 84

d. Production of Space and Mapping.................................. 89

e. Conclusion................................................. 98

6. Chapter IV: Conclusion and Future Work............................... 100

7. Bibliography................................................. 104

8. Appendix A: Interview Guide ...................................... 111

9. Appendix B: Sample Table .......................................... 113

10. Appendix C: Maps.............................................. 114 


\section{Chapter I: Introduction and Background}

\section{Background}

Urban spatial arrangements are subject to many different forces including capital investments, history, policy and the presence of local and external communities. Presence and visibility of different communities is contingent on their power to occupy and be safe in different spaces. Cities are designed and built for those who are able to occupy them the most, those who follow hegemonic ideas of citizenship and behavior.

Underrepresented and marginalized communities are less likely to inhabit urban locations where they might be subject to policing or discrimination. Communities of color and sexual and gender minorities are examples of groups that have had to carve out specific locations in order to create and maintain community, remain safe and feel included. Many of these communities are geographically bound due to a variety of reasons such as discrimination, historical residential restrictions, and interest in maintaining community. Queer people, particularly gay men, have occupied neighborhoods in cities around the country in order to avoid marginalization and to promote a sense of unity with other queer people.

Sexual and gender minorities have always been a part of the urban landscape. Their visibility, however, has increased particularly in the past sixty years. During World War II, many women migrated to urban centers in order to work in factories, while men had joined the military in order to support the way efforts. These mostly gendersegregated spaces allowed for the concentration of gay and lesbians. This, at the same 
time, facilitated the development of communities organized around sexual orientation or gender identity (Bérubé, 2010). Even though the presence of queer people has been widely known and documented throughout history, this era marks the beginning of the visibility of lesbian, gay, bisexual, transgender and queer (LGBTQ) individuals as communities across the United States. During the 1950s, with the rise of the anticommunist McCarthy era and a push for blanketed domesticity, many LGBT people had to go unnoticed, developing underground bars and shops. According to Wolfe, "lesbian communities and lesbian bars as 'public places' to gather developed in a time of backlash" (1997: 312). After several decades, queer communities have made many social and political advances towards a sense of equality. Along with this progress, there has been a decline in the number of queer-specific spaces across the county (Podmore, 2006; Nash, 2013; Brown, 2013; Doan and Higgins, 2011). This project explores the ways in which queer women in Portland perceive this phenomenon and the relationship between these public spaces and community. At the same time, this research is interested in the importance that private and cyber spaces have on queer communities in Portland.

Even though this research explores all different types of queer spaces, bars are often highlighted both by academia and popular media due to their public presence and historical relevance. In a patriarchal hetero-sexist society, these spaces have served as community centers where women have developed friendships and recognized political, social, and personal connections with other queer people. Since being openly queer in urban environments has not always been safe, these spaces have been crucial in developing a sense of place and belonging in urban landscapes. With the growing 
acceptance of mainstream queer political goals such as same-sex marriage and openness in the military, as well as a normalization of gay and lesbian individuals in the media, queer spaces and neighborhoods have become economic and "cultural" assets in metropolitan areas (Florida, 2003; Bell and Binnie, 2004).In recent years, however, the number of queer women-specific public spaces has declined across the country. This decline has been accompanied by growing acceptance of queer people in the media. This research suggests that there is a connection between the decline of spaces and the acceptance of LGBTQ people, but it does not imply that queer women's communities do not want or need specific public spaces. Given the importance of bars and community centers for LGBTQ people in the United States, research should continue to address the ways in which this decline has affected queer communities around the country. This paper explores this decline and its impact on communities, as well as the alternatives that have emerged. Beyond that, it tries to explore the ways in which we conceive of urban space for marginalized and non-hegemonic populations.

\section{Research}

Spaces where people can interact, meet and share affinities are important to develop a sense of belonging. Most of the research that has focused on queer space has mentioned the difficulty of mapping queer women's spatial patterns, particularly in an era of declining public spaces. Utilizing common conceptions of space in terms of neighborhoods and consumption locations, queer women appear almost invisible in most cities across the United States (Castells, 1983; Peace, 2001). The initial purpose of this 
research was to identify the ways in which the decline of queer women-specific space in Portland has affected the development of a women's community based on a queer identity. In the process of developing the research, however, the purpose shifted to better understanding the spaces that queer women occupy and the reasons why these spaces have disappeared. At the same time, I was interested in building a better framework for understanding queer women's geographies. The literature suggests that queer women are placeless, so I was interested in dissecting the actual spaces that they occupy, as well as a theoretical structure that is able to include spaces at different scales and different forms. Through interviews in which participants are asked to draw a map of what they consider to be queer women's spaces, I attempted to create an avenue for queer women to visualize the spaces that they consider theirs.

Initially, I had envisioned the first research question as addressing the relationship between identity (specifically "queer," but others such as race and class as well), space and community. The second question was intended to address the ways in which changing identity patterns (from lesbian to queer, for example) had affected the need and desire for spaces. As the project evolved, the research questions did too. The overall purpose of the research is to understand queer women's spatial patterns in the context of declining queer-specific public spaces, of an increase in acceptance of queer people in the mainstream, and a complexity in identities within queer circles. The main research questions that this paper attempts to answer, then, are: a) what do queer women's spaces in Portland actually look like? b) What is the role of queer women-specific public spaces in queer women's lives in the context of an accepting socio-political climate? c) What are 
the roles of gender identity, race, class and age in these communities and spaces? Along with these questions, this research is also interested in the theoretical consequences of the results of this research. The theoretical and methodological questions that I explore are: How do the experiences of queer women in Portland translate into spatial frameworks of marginalized communities? And, finally, what role can mapping and representations of space play in the ways in which queer women occupy space?

The first three questions will address the topic of queer women's spaces in the context of Portland. The issues at hand attempt to illustrate the state of queer women's communities in the city and their relationship to urban spaces. At the same time, the research will show how race, class, age, and gender identity affect both community development and appropriation of space. Even though the research focuses on Portland specifically, these questions will have consequences beyond the scope of the Pacific Northwest. Since Portland is perceived as a progressive place in terms of gender and sexuality, it is a ripe place to understand how these issues affect the way the city is arranged and used. The decline of queer spaces in Portland is reflective of a phenomenon occurring in the rest of the Unites States, which is why this research will serve to better understand queer geographical patterns outside Portland.

The last two questions will be primarily addressed in the third chapter of this research. This chapter will be theoretical and methodological in nature, focusing on the broader consequences of studying and understanding cities through the eyes of queer women in Portland. By exploring the ways in which certain marginalized communities 
utilize urban spaces and, more importantly, conceive of them, this research begins to rethink the importance of public, abstract and temporary spaces in the development of communities and movements based around identity. Finally, I will also explore how the maps drawn by participants are telling of the deficiencies of current academic literature around urban space. Frameworks that ignore different scales, different forms and temporary spaces are not as useful in understanding queer women's spatial patterns in American cities. Exploring these different maps can be crucial in reevaluating the importance of different types of understandings of urban landscapes based on identity.

\section{Frameworks}

This research attempts to address issues of identity and space within a feminist, queer and critical framework. As a queer feminist researcher, I recognize that my interest in this topic is both personal and academic. I also recognize that the choice of topic and method are specific to my experiences based on my identities, and not solely based on an academic curiosity. The decision to conduct map-making interviews was intentional: personal stories and spatial perspectives are powerful accounts of the ways in which cities operate. Planners and policy makers are often not interested in the opinions and input of urban dwellers because day-to-day lives are seen as mundane and personal perspectives are seen as biased. Following Lefebvre's interest in the "everyday life," the methodology tries to emphasize stories over quantitative data or geographical accuracy. Allowing participants to visualize the city based on their experiences is a way of 
reclaiming urban spaces that often exclude non-hegemonic bodies. Utilizing a 'queer theory' framework, I also hope to understand how identity is developed by queer women in relation to their environment and the political context. This framework also allows for a nuanced understanding of gender identity and sexuality.

The term 'queer' is a rather new theoretical term utilized to refer to identities that problematize normative understandings of sex, gender, gender expression and sexuality. With the poststructural challenge to essentialist notions of identity, 'queer' emerged as a non-identification, one that is provisional and constantly in flux. Based on Foucault's studies on sexuality, Judith Butler (1990) and Eve Sedgwick (1990) revolutionized notions of gender and sexual identity by challenging the heterosexual/homosexual binary and by recognizing gender as "the repeated stylization of the body, a set of repeated acts within a highly rigid regulatory framework that congeal over time to produce the appearance of substance, of a natural sort of being” (Butler, 1990:33). These critiques of common notions of gender also challenge identifying heterosexuality as normal and homosexuality as deviant. For the purposes of this project, I utilize the identity 'queer' as any disruption of normative conceptions of gender and sexuality, keeping in mind that the identities are relational to other identities, institutions and space.

Some have argued that 'queerness' "shakes the ground on which gay and lesbian politics has been built, taking apart the ideas of a 'sexual minority' and a 'gay community"' (Gamson, 1995). The term 'queer' is not tied to a set of sexual practices that occur in private spaces; rather, it adds nuance to understandings of gender and 
sexuality. These theorizations can be expanded to the realm of geography. As Browne suggests, queer geographies demand an understanding that goes beyond the binary of heterosexual/homosexual spaces (2006). Rather than simply investigating LGBTQ public spaces, this research understands place and space as relational concepts that are affected by the presence of queer bodies.

For the purposes of this research, I utilize the term 'queer' as an identity signifying the disruption of normative conceptions of gender and sexuality, keeping in mind that sexuality and gender are intersected with other identities such as race and class. The term queer will be used interchangeably with LGBTQ. It is crucial, however, to recognize the different communities within the LGBTQ spectrum and the vast political and power differentials between white gay men, for example, and transgender women of color. For this reason, I also want to make a distinction between sexual and gender minorities. Sexual minorities (mostly addressed as gay, lesbian, bisexual and queer) refer to those people who deviate from traditional relationships that are composed of two different-gendered partners. Gender minorities, then, is a term used to refer to individuals who do not identify with the gender assigned at birth based on physical and biological characteristics. The term that I will use in this paper to describe gender minorities is trans, an umbrella term that refers to people who do not identify with their gender assigned at birth, a different gender, or no gender at all. This research was inclusive of all people who identified as women regardless of their gender assigned at birth, but does not intend to speak specifically to the experiences of trans women in Portland. As an overall 
terminology, I will use queer to speak of participants as a whole, using specific language for individuals when requested.

Also crucial in the understanding of identities is the concept of intersectionality. Perhaps one of the most important contributions of feminist theory to social science, this concept was developed by Crenshaw (1991) and further expanded by Collins (2000). Intersectionality refers to the ways in which systems and patterns of oppression interact to affect specific individuals in depending on their race, class, gender, sexuality, age, and other identities and characteristics. This framework is particularly useful in understanding how women with non-normative sexualities might experience urban space differently than queer and straight men, while also remembering that all bodies are raced and classed. The experiences of individuals are unique depending on their backgrounds and intersecting identities. Any research that attempts to be critical should recognize bodies as simultaneously sexed, raced, classed and gendered (Oswin, 2008). In a city like Portland, which is largely white, people of color have the potential to be erased.

Queer identities are one way in which people relate to each other and form communities. Much has been written about the importance of communities in urban settings, particularly those based on neighborhoods. Throughout the history of cities, there has been a debate on whether modern life and urban settings have either increased or diminished people's ability to relate to each other (Driskell and Lyon, 2002). According to Driskell and Lyon, "much of the debate on whether lost community can be regained focuses on the degree to which community can exist without a local place" 
(2002: 374). This research takes part in this debate, incorporating the role not only of identity in the development of community, but also of particular interests within those identities. The framework that I use in this research makes a distinction between placebased and shared-space communities. This research conceives queer women's communities as ones that share space, even if those spaces are private or online.

The spatial framework, which will be covered extensively in the third chapter, is based on understanding space in relation to social interactions. Rather than conceiving space as a backdrop for social and economic relations, I attempt to understand space as an important actor in the development of queer identities in Portland and beyond. Utilizing Doreen Massey's analogy of space, I visualize spaces as nodes of social relations that interact in specific locations (Massey, 2005). At the same time, I hope to add complexity to these understandings of space by incorporating different scales and types of space onto the same maps and discussion of urban space. Overall, this research relies on critical, feminist and queer geography in a practical and theoretical sense. These different theoretical frameworks shape my perspectives as a researcher and influence the method, the questions, and the overall goal of this paper.

This thesis is composed of two major parts that focus on different aspects of the research. The second chapter, Queer Women's Space in Portland, OR, will address the particularity of queer women's spaces and communities in Portland, Oregon. This section will cover the literature that precedes this research, including academic work that has studied queer 
(mostly gay) communities and neighborhoods in cities across the country, as well as literature that addresses issues of identity and space. Then, I will explain the research project in detail, covering the process, the sample, methodology and framework. The major themes that emerged from the interviews will then be addressed in detail, along with quotes from participant's interviews. Finally, I will conclude the chapter by discussing the relevance of the findings, as well as the need for further research around issues of identity and urban space. This chapter will speak directly to the issues raised in the interviews and the specific topic of queer women's spaces in Portland.

The third chapter of this paper will address the implications of this research on spatial frameworks. This section will cover questions that are particularly concerned with the ways in which urban space is conceived by participants, particularly in a context when there are no specific permanent public spaces designed for or by them. Because of the lack of specific spaces for queer women in Portland, the participants presented a set of alternative spaces that are difficult to map with traditional Cartesian cartographic tools. Such spaces include sidewalks, homes, bedrooms, the internet, and temporary events across the city. This chapter will give an overview of spatial literature, and well as a particular examination of the maps and the answers that addressed issues of space. I will talk about the process of mapping and the different types of space that were represented through the interviews. Finally, I will discuss the possibilities of reframing space through participant's maps. The process of mapping different spaces allowed participants to describe experiences that are often erased by the literature on queer spaces. 


\section{Chapter II: Queer Women's Space in Portland, OR}

\section{Introduction}

This chapter will explore the specific questions: what do queer women's spaces in Portland actually look like? What is the role of queer women-specific public spaces in queer women's lives in the context of an accepting socio-political climate? What are the roles of gender identity, race, class and age in these spaces? In order to answer these questions, I conducted 15 map-making interviews that explored issues of community, identity, and relationship to place and space. This research allowed participants to visualize and conceptualize queer women's spaces in whatever way they wanted. This was telling of the spatial interactions and relationships that queer women have with the city and each other. The specific spaces that were mentioned varied in scale, shape and form. At the same time, these maps and interviews showed that the communities that queer women develop are not based on public spaces but are more determined by demographics and the internet. The idea of a singular community was dismissed by most participants, citing classism, racism, ageism and lack of interest in developing community. These responses have led me to conclude that queer women utilize private and cyber spaces in order to develop community, and there is less of an interest in finding public spaces to fulfill these needs. A changing political and social climate and divisions within queer communities in the city are some of the reasons why the number of queerspecific public spaces has declined. 
Portland is a medium sized city in the Pacific Northwest that has recently gained a national reputation as a hip, environmentally conscious and politically progressive town filled with young people working service jobs and playing indie music. This perception has been promoted by the media with shows like Portlandia as well as the local government. Many of these ideas of Portland, however, are not supported by lived experiences and academic research. In the past thirty years, the city has received a large influx of young college-educated people despite the lack of economic opportunities. These migrants have cited other reasons, such as amenities, for moving to Portland (See Jurjevich and Schrock, 2012). Portland, then, does not yet have an economic infrastructure to maintain the influx of young, college-educated people. While more and more of these individuals move into the city, older residents, particularly low income and communities of color, are pushed out of Portland. The history of the African American community in Portland, and in Oregon more broadly, has been one of exclusion and discrimination. The relatively small black community of Portland has suffered displacement from the historically black neighborhood, Albina (Gibson, 2007). Today, Portland is one of the whitest major American cities (Hammond, 2009), with a black population that has never been higher than 7\% (Gibson, 2007). Portland's reputation, then, often erases issues of race and economic sustainability.

Portland, time and time again, been rated as a queer-friendly city by several rankings on the internet such as Vocativ, Nerd Wallet, and The Daily Beast, just to name a few. The city is known for having resources for transgender individuals (See Willson, 2014), as well as a large number of queer people. More importantly, however, Portland 
is perceived as a tolerant and progressive city around issues of gender and sexuality. For this reason, it is surprising that the city has limited spaces geared specifically for queer folks. Aside from a few night clubs directed towards gay men, a couple of queer bars, and one community center, there are no specific spaces owned, run, and dedicated to queer communities in Portland. More specifically, there are no queer women-specific places in the city. Keeping with the literature, queer women in Portland are less likely to own, frequent, or develop a public space based on their identity. Particularly in recent years, many bars, bookstores and community spaces have closed their door.

Portland, Oregon, has not been an exception to the trend of decline of queer spaces. The sole queer women's bar in Portland, the Egyptian Room, closed down in 2010 and no attempts have been made, as far as I am aware, to open another space that serves these communities specifically. Despite its allegedly progressive politics and existence of subcultures, no queer women-specific public spaces exist. As I sit in a Northeast Portland coffee shop, however, I recognize several visibly-queer individuals and couples. Does this mean that all spaces are now accessible to queer women? A recent article on Marketplace, a national radio show that focuses on business, addressed the decline of lesbian bars around the country with a focus on Portland (Prichep, 2014). This article referred to an event called Temporary Lesbian Bar that happens once a month in a bar in North Portland. The author interviews several people, some who lament the disappearance of permanent public spaces while others who appreciate the move to online forums. As the article points out, the climate around queer women spaces is changing, permanent public spaces are in decline but they seem to have been substituted 
by the internet and temporary events. The article, however, does not address the impact that this has on communities and the overall response to this changing environment in Portland specifically.

This project, then, examines how Portland's reputation as a queer-friendly city is accompanied by a lack of public spaces dedicated specifically to queer women. The coexistence of these two characteristics is intriguing given the history of bars and community centers in queer communities. While conducting the research, I recognized that there was a possibility that the lack of spaces is simply not a concern for queer people in Portland. This, however, was equally as relevant because it might have meant that queer folks in Portland did not consider those spaces as necessary as before. This reflects issues raised by literature on community that questions the importance of local communities with the rise of the internet (Driskell and Lyon, 2002). Before exploring the results and the meaning of this decline, I want detail the research that has centered queer and queer women's geographies.

\section{Literature Review}

\section{Queer Women's Spaces}

Prior to the 1970s, geographers conceived of space as merely the material backdrop for social relations and processes (for a detailed evolution of the concept of space, see Smith, 2008). The Marxian critique of the 1970s, along with poststructuralist influences, forced 
geographers to rethink the relationship between social identities and space. In some contemporary research and theorizing,

space is understood to play an active role in the constitution and reproduction of social identities and, vice versa, social identities, meanings and relations are recognized as producing material and symbolic or metaphorical spaces (Valentine, 2002: 146).

With this theoretical turn, researchers began focusing on issues of race, class, gender and sexuality in urban spaces. Utilizing queer theory, Oswin (2008) suggests that geography needs to move beyond sexual politics and engage with feminist, postcolonial and critical race theory and move away from simply describing the ways in which queer people arrange themselves in space.

The study of queer bodies in major Western cities began as an exploration of 'gay ghettoes.' In the 1970s and 1980s, researchers began noticing spatial formations based on sexual and gender identities. Empirical studies of the Castro in San Francisco (Castells, 1983), the Marigny neighborhood in New Orleans (Knopp, 1998) and the gay village on Canal Street in Manchester (Quilley, 1995) are examples of these early explorations of queer spatial formations. These studies addressed the ways in which primarily middleclass white gay men formed communities in particular neighborhoods in large cities, often taking part in gentrification and displacement of low-income lesbians and communities of color (Knopp, 1998). These neighborhoods and the overall acceptance of queer people in cities across America have been seen as a cultural asset (Florida, 2003; Bell and Binnie, 2004) in metropolitan areas. 
Most of the studies on queer or gay spaces have followed the heterosexual/homosexual binaries regarding space and have mostly neglected to address issues of class and race within the LGBT community. Browne (2006) has argued that we need to challenge 'gay ghettoes' and homonormativity, as well as the concept of inclusion itself because of the people that it leaves behind. Browne is also interested in differentiating between 'queer geographies' and 'geographies of sexualities' (2006) by inviting other academics to move beyond classifying space as either heterosexual or homosexual, and understanding the relationship between people, space, and the landscape.

The studies of lesbian or queer women's space have been significantly more limited than those exploring gay men's space in urban settings. Castells (1983) argued that lesbians "tend not to concentrate in a given territory, but establish social and interpersonal networks" (140). His conception of queer women in San Francisco assumed that lesbians behaved primarily as women, meaning that they were less likely to appropriate public space. Since women have often been relegated to private spheres, their presence in public spaces has not been as apparent as men's. In other words, Castells considered women (including lesbians) to be "placeless," and unable to appropriate space due to the ways in which they were raised.

Castells has not been the only one to point out these challenges, others have also recognized the difficulties of researching queer women's space. Peace believes that it might be "useful to reflect on the question of whether the category of lesbian constitutes 
an identifiably "spatialized," mappable, "real” identity group or whether, [...] it is not geographical" (2001). Adler and Brenner (1992), in response to Castell's initial research, have emphasized the specific issues surrounding women's capacity to dominate public space: mainly, they suggest that women do not have equal access to capital that would allow them to own or operate businesses that would simplify mapping them.

Additionally, there is an added threat of male violence that discourages women from claiming space (Adler and Brenner, 1992).

Along with this emphasis on the possible challenges to women's ability to claim space, Adler and Brenner found that queer women's space actually existed but in a quasiunderground fashion because it lacked visibility, community activity and organization. The lesbian community was "less place-based" than the gay male community (1992). Most of the research up until Rothenberg's (1995) study "found that lesbian communities were constituted in space through fluid informal networks that linked a variety of public and private sites and, as a result, were quasi-underground in character" (Podmore, 2006). In her analysis of the Park Slope neighborhood in New York City, Rothenberg concluded that lesbians had created "a recognizable social space" (1995) that was not based on consumption locations in comparison with gay men's spaces. Bookstores, cafes and support groups were some of the examples of the places that queer women frequented and made their own even if they were not originally designed as queer women-specific spaces. 
In the past few years, there has been a decline on the existence of queer women's public spaces, bars in particular, across the country. Popular media and academic research (Podmore, 2006; Nash, 2013; Brown, 2013; Doan and Higgins, 2011) have documented the decline of queer public spaces and neighborhoods in the context of assimilation, changing identities and gentrification. Other studies have also reported the declining visibility of lesbians in existing gay establishments and neighborhoods (Casey, 2004), and the importance of homes in the development of community (Elwood, 2000). However, the literature points to a larger decline of queer spaces beyond the invisibility of queer women in existing gay locations. Through a long-range historical case study of Montreal's gay neighborhoods, Podmore found that visible queer women's space declined in the early 1990s due to neighborhood change and the shift to a 'queer' identification (2006). According to the author, the fragility of the 'queer' category marked difficulties with establishing commonalities with other queer women. Even though Podmore addresses the particular decline of queer women's spaces, other researchers have begun exploring the changing nature of gay or queer neighborhoods in general.

Nash (2013) argues that, when attempting to understand changing gay neighborhoods,

one needs to be attentive to what many commentators assert is an emerging generation gap amongst and between certain segments of the LGBT population around notions of identity, 'sexual orientation', masculinities and the ongoing political and social purpose of the traditional gay Village (2013: 243). 
Her research in Toronto's gay village explores what she calls the age of 'post-mos,' referring to a generation of younger LGBTQ people whose needs are different than previous generations. Based on a content analysis of articles, websites, comments and blogs, Nash argues that "post-mos" are no longer in need of a neighborhood that supports their lifestyle away from the mainstream. This generation, according to the author, occupies spaces like the internet to meet other like-minded individuals rather than bars and community spaces that were crucial in a time where the outside world was not accepting or accommodating to their particular lifestyles. The implications of this research suggest that queer spaces are declining because of a generational shift in the context of social and political acceptance of queers in the mainstream.

Both Nash (2013) and Podmore (2011) offer specific examples of the decline of queer-specific public urban spaces in cities in North America. Queer spaces and queer neighborhoods in particular seem to have lost their relevance in an era in which there is greater assimilation as well as greater fracturing in the LGBTQ community based on other identities such as race and gender identity (Ghaziani, 2011). Brown (2013) reviews the literature surrounding the decline of the gay neighborhood and raises the question of whether the gay neighborhood has also lost its theoretical and intellectual importance in the same manner that it has lost its cultural significance. These studies are crucial in framing this research, recognizing the forces that have caused the decline of public spaces that serve primarily queer people, while questioning the causes for this phenomenon and the theoretical consequences. 
Using Atlanta as an example, Doan and Higgins (2011) argue that the decline in queer spaces is due to gentrification and growing assimilation of LGBTQ people into the mainstream. Their research is crucial in incorporating an economic dimension to the presence of queer individuals in particular neighborhoods and public spaces. In the context of Portland, this research has also traced a movement of queer women from one part of the city to several different areas. This particular study, however, does not focus on the specific neighborhoods and migration of queer people within the city. More specifically, I am interested in understanding some of the issues with conceptualizing lesbian space simply as residences and consumption spaces. Even though the literature that addresses the decline of queer public spaces and neighborhoods across North America is relevant to understand the overall changes in the ways in which queers occupy space, it does not offer a new framework to understand the spaces that are being used by LGBTQ people. Bowne (2006), for example, suggests that when conceiving space in the hetero/homosexual binary, some spaces get erased. By classifying some neighborhoods and bars as "gay" or "queer," we also classify all other spaces as heterosexual. This research attempts to understand other types of spaces such as homes and the internet that do not necessarily fall within this binary of hetero/homosexual but serve as an alternative to the spaces that seem to be in decline. It has become clear that queer women-specific consumption spaces are not enough to understand the ways in which these individuals form communities. 


\section{Community: Identity, Interest and Place.}

The literature that addresses queer spaces rarely addresses their relationship to 'community.' According to Defilippis and Saegert, "people who share space together build a common set of experiences, that when accumulated over time and in different parts of life form much of the basis of people's support networks in their daily lives" (2008: 4). Space, in whatever form, allows for people to develop connections with others with whom they might share an interest or identity. There has been a long debate about the importance of the "local" in the development of communities, particularly in cities. There has been much written throughout the history of urban studies and planning about the effects of urbanization in the development of communities within cities. In the United States, the Chicago School had an interest in understanding the sociology of cities through the study of crime and other social problems. This perspective envisioned the city as a living organism. Wirth, for example, believed that the diversity and heterogeneous nature of cities would lead to the loosening of community ties and the "replacement by mechanisms of formal and social control" (Parker, 2004). The argument of 'community loss' put forth by some of these theorists emphasized the destruction of ties between individuals as a consequence of modernization.

After World War II, Jane Jacobs began writing about urban environments in the context of suburban expansion and migration outside of the city. For Jacobs, urban communities were formed due to density and diversity (Parker, 2004). Living in the same neighborhood or frequenting similar spaces in a city meant a greater likelihood of 
forming meaningful communities and creating safe spaces. For Jacobs, sidewalks and the stores and business that line them are crucial in the development of successful and safe urban living (Jacobs, 1961). Jacobs's urbanism was meant to exemplify the importance of public spaces and dense cities in people's relationships to each other. Many scholars continue to insist that 'community' needs to be bound to a physical space (Poplin, 1979; Wilkinson, 1991). Wilkinson (1991) believes that the territorial specificity of community has diminished, and suggests that webs of interaction determine the boundaries of community. The decreased importance of proximity in the development of community has also given way to virtual communities (Nieckarz, 2005).

With the development of the internet and cyberspaces, some have argued that it is necessary to move beyond the discussion of 'community loss' as an either/or problem (Reymers, 2002). The internet provides a space for the development of both place-based and interest-based communities to connect and develop. Virtual communities require a shared interest amongst participants, while in geographic communities, "no preexisting interests need be present for a community to take shape; the simple fact of sharing the same space can create those interests" (Nieckarz, 2005). However, interest-based communities are not the only ones that exist beyond territorial settings.

Being part of the same social categorization (e.g. ethnic background, race, class, and gender identity) is one way that communities are formed, particularly those based on identity (Ren, 2007). These communities can be both geographical or not. A lot of these communities, particularly those based around class and race had lived in the same 
neighborhoods; there was an element of common territoriality to a lot of these communities. Patricia Hill Collins argues that sociology has naturalized and normalized views that "situate community as geographically specific, culturally homogenous, and inherently apolitical" (2010: 9). Queer communities, then, do not necessarily arrange in territorial clusters, and therefore require alternative ways of conceptualizing communitybuilding. Particularly with the rise of internet usage and various forms of social media, many people identify with communities that may or may not be geographically based.

The concept of collective-identity offers one approach to understand the reasons and forms in which individuals build non-place-based communities. Collective identity is defined as an "individual's cognitive, moral, and emotional connection with a broader community, category, practice, or institution" (Polletta and Jasper, 2001). In their study of lesbian feminist mobilization, Taylor and Whittier defined collective identity as a common definition of a group that lets members define "who we are" (1992: 110-111). Collective identity, then, develops boundaries between those who are 'in' or 'out.' Taylor and Whittier concluded that identity communities were formed through boundaryconstruction, the development of consciousness and negotiation (1992). This emphasizes the dialectical relationship between identity, community and forces outside of that grouping.

This framework, however, has been challenged by people studying recent queer movements (Gamson, 1995; Ghaziani, 2011). With poststructural critiques, it became clear that "fixed identity categories are both the basis for oppression and the basis for 
political power" (Gamson, 1995: 391). According to the literature, the LGBTQ movement has evolved from a 'closet' and 'coming out' to a 'post-gay' framework that emphasizes difference within the community (Slagle, 1995; Ghaziani, 2011). Ghaziani describes this 'post-gay society' (beginning in 1998) as “distinguished by an increasing assimilation of gays into the mainstream alongside rapid internal diversification" (2011:103). This author suggests that current identity construction in the LGBT movement is less focused on marking differences with non-queer individuals, and is interested in developing bridges with allies and people outside the movement. This shift in an overall queer identity possible signifies the fracturing of queer communities.

Brown-Saracino (2011) states that her "data complicate a dominant premise in community studies that suggests that social identities foster community and that the formal institutions and ties that fuel community in turn reinforce existing identities." In her study, Brown-Saracino discusses a certain loss of community ties in the queer women's community in Ithaca. These transformations, according to the author, have given way to an 'ambient community', a type of organization that stands in stark contrast to a 'ghetto' or enclave. The ambient community is based on a loose web of connections between lesbians that either reject or no-longer need formalized organizations or spaces. As argued by Ghaziani (2011), these transformations cause and are caused by greater assimilation and fracturing in the LGBTQ community. A critique of the emphasis on assimilation and coalition-building has been raised by several authors (See Dugan, 2002; Ward, 2008) because it implies that assimilation can be achieved by those members 
whose other identities are hegemonic; while racial/ethnic minorities, trans people, and those with less access to capital remain at the margins.

Rothblum, Balsam and Mickey (2004) have found that queer women have greater spatial mobility, less involvement in social institutions (e.g. churches) and fewer relationships with their families than straight women. This might suggest that queer women are more in need for community building than other groups with larger support networks. Some earlier research exploring lesbian communities addressed the importance and difficulties of creating these communities in contrast to other groups (Eder, 1995; Franzen, 1993; Lockard, 1986). Some current empirical research continues to indicate that queer women have had difficulties in creating and developing a queer womenspecific community, except that it is less about oppressive systems, and more about the differences within the movement and the focus on other commonalities as basis for community building (Rothblum, 2010; Brown-Saracino, 2011).

The literature, then, has not been able to identify the reasons why or the ways in which queer women use space. Some have recognized the decline of public spaces but few have articulated an alternative for understanding the ways in which queer women occupy space. It appears that there is not a framework that can allow us to conceive of a series of disparate spaces at different scales. It also seems that queer spaces are beginning to lose their relevance as community centers, making them less profitable and less accessible to queer communities around the city and the country. Interest-based 
communities have evolved with the development of online social networks, suggesting a transformation in the ways in which people interact with and within space. The consequences of the decline of queer spaces and its effect on the development of communities, however, has not been extensively researched or addressed in the literature. This research begins to understand the meaning of queer spaces in Portland, as well as the ways in which these communities utilize private and more abstract spaces.

\section{Method}

This research is my master's thesis project and it arose out of curiosity over space and issues of sexuality. As a queer woman, I was interested in the ways in which community is formed when no spaces are particularly designed for its creation or maintenance. More importantly, I was interested in the ways in which queer women conceive of Portland, a city with a reputation as a safe and accepting place for queer and gender non-conforming individuals. The ways in which people understand their own location in relation to others, the environment and the socio-political relations around them were at the heart of this research. In order to attain perspectives that informed these interests, I opted for developing a qualitative approach largely based on interviews in which participants were asked to draw maps of what they consider to be queer women spaces in Portland. These maps could be visualized in whatever form and did not need to be scaled or "accurately" reflect Portland's streets or public spaces. By allowing 
participants to speak about their own spaces and tell their own stories, the research was able to gather a varied perspective on queer women spaces and communities in Portland.

The development of maps through interviews has been explored in several disciplines, including urban studies. Cognitive or mental mapping can be defined as "the psychological transformations by which an individual acquires, stores, recalls, and decodes information about the relative locations and attributes of the phenomena in his [sic] everyday spatial environment" (Downs \& Stea, 1973: 7). These maps are not just mental structures that attempt to represent the built environment; they also contain and construct meaning and values (Kitchin, 1994). These constructions are able to provide us insight into an individual's perceived spaces, as well as the meaning attached to them. These mental conceptions are crucial in understanding space because they affect individual behavior (Kitchin, 1994). At the same time, they are able to reflect a set of diverse spaces and locations that are not identifiable in scaled mapping such as homes and temporary spaces.

Within the context of the city, maps have been "used in attempts to tame the urban labyrinth, and to represent its spaces as 'legible' and 'knowable'... transform its messy incoherence’s into a fixed graphic representation” (Pinder 1996:407). Representations of space, such as maps, are used to create a very particular understanding of space, determined by those who have the tools to represent spaces. Maps, however, can serve an unlimited number of purposes and can be used as tools of community empowerment, artistic expression, resistance, et cetera. Providing alternative forms of 
representing space can be subversive and powerful. Moving beyond the scientific, geometrical, and appropriate-scale techniques that are put forth by normative cartographers, we can explore very distinct modes of depicting and representing space that are useful both to a specific community as well as for the general population that is made invisible by traditional mapping. In "Subverting Cartography; the situationists and maps of the city," Pinder proposes a "tactical, artistic and political use of urban maps and mapping" $(411,1993)$. These maps can be a source of power and understanding for marginalized groups. Often times, the act of representing space is denied to the bodies that interact with said space. Non-normative groups" ability to "map" their space is linked to their difficulty with claiming space and carving space.

Anthropologists and critical geographers have used map-making projects to address issues of gender in cities. William Leap, who has done extensive work on gay men's relationship to space in Washington, D.C., conducted interviews in which he asked respondents to draw a "gay map of Washington" and the ways in which the destruction of some bars had affected the city (Leap, 2009). By asking participants to draw a map, he was able to develop an interview and a conversation that was significant to his research questions. When attempting to understand space and place, neither maps nor interviews alone would have been able to inform his study. Edelman has followed a similar technique for exploring transgender spaces in Washington, D.C. (Edelman, 2012). Mapping has been used to better understand the ways in which certain communities experience space, but little has been written about the effects of mapping on participants or conceptions of space. This research attempts to use this method as a way for queer 
women to visualize their spaces in Portland, as well as a way to understand the diversity of scales and forms that queer spaces take.

I began the interviews by providing participants a blank sheet of paper and asking them to draw a map of what they consider to be queer women's space in Portland, OR. Due to the lack of actual physical location of public spaces in the city, participants depicted locations that are not easily identifiable on a city map (e.g, their homes, specific buildings or rooms, bodies or other abstract conceptualizations of space). After they completed the map-making process, I asked a list of pre-established questions addressing issues of identity, space, and community. Through these questions, I was able to gather their personal stories in Portland, Oregon as well as their relationships to certain spaces and queer communities. The maps are crucial in launching the conversation and identifying spaces that are relevant for them as individuals and for other queer women in Portland. At the same time, this process can be a way to visualize and reclaim spaces that are often not represented in normative maps. The maps themselves are able to exemplify issues of representation, issues of community, identity, and personal experience.

\section{Sample (See Appendix B for table)}

This paper is based on 15 in-depth interviews with queer-identified women who live in the Portland metropolitan area, conducted from February to August, 2014. Before the interviews, I went through the Internal Review Board and developed standards intended to protect participant's confidentiality. Over twenty years ago, when Adler and Brenner wrote a response article to Castells based on the experiences of lesbians in 
Portland, they chose not to include the name of the city or any of the locations because it could put participants at risk. Today, those concerns have been minimized; this is telling about the changing climate for queer people. This is not to say, however, that there are no risks or safety concerns when working with queer and trans individuals; particularly for trans people, city spaces continue to be places of gender regulation and policing (Edelman, 2012). The overall visibility and acceptance of queer people, however, is apparent even in the ways in which we conduct research at the University level.

One of the difficulties of studying queer women is that they are not geographically bound to a specific location, and there is no directory that would allow for a representative sample. I recruited participants by posting flyers at certain queer friendly physical spaces. I also shared the flyer with different organizations and social groups that posted it on their Facebook pages and other social networking spaces. This recruitment method is subject to self-selection bias and a disproportionately younger sample, as younger individuals may feel more comfortable with accessing these spaces. I then developed a snowball sample with some of the participants who had already responded. Snowball samples can be useful when studying community because it allows the researcher to understand the network of connections that is already in place. However, this can be limiting because most people tend to surround themselves with people who have similar experiences. Browne suggests that snowball samples in queer communities can be useful in identifying networks within the group, but that researchers need to be aware of the potential for exclusion of some individuals that might not be part of this network (2005). 
Due to issues of representation that arose both from self-selection bias and snowball sampling, I made a particular effort to reach out to women of color. Since Portland is a largely white city, I wanted to better understand the ways in which women of color conceive the space differently from their white counterparts. Queer women of color are an even more difficult population to reach, particularly in Portland. Out of fifteen participants, five were women of color. Even though this is not enough to make generalizations about the queer and trans women's experiences in Portland, it definitely enriched the research by surfacing some of the deep racial tensions in the city.

As mentioned before, the research consists of fifteen interviews with people who self-identified as queer women, all residents of the Portland metropolitan area. Their ages ranged from 23 to 52 , with a median age of 31.2 , and a mean of 28 . Ten of the participants were white, while five were women of color. Most participants identified as queer, while two identified as bisexual, and one as pansexual. Fourteen participants identified as cisgender while one identified as transgender. Most of the participants identified as being part of a queer community while a few others did not consider themselves involved at all. Some of the participants were students, others worked in the service industry, others were professionals, and two were unemployed. This sample was not intended to be representative of queer women in Portland in general, but it is representative of different experiences: a wide range of ages, ethnic and racial backgrounds, and gender and sexual identities. The interviews were conducted during the spring and summer of 2014. The interviews were then transcribed and coded for themes. The maps served as conversation starters as well as visual representations of the issues 
addressed in the interviews. The process of developing the maps was difficult for some participants; some mentioned that they had never thought about the spaces that they occupy as queer or specifically designed for them.

Interviews that have a map component allow for participants to explore their senses of place and geography in a particular setting based on a particular identity. The results from the interviews are telling of many different issues and experiences based on gender and sexuality, but also based on race and age. The following section will introduce and explore the different themes that were most salient in the interviews. These themes are particularly concerned with issues of identity and community and they seek to address the questions posed at the beginning of the chapter: What do queer women's spaces in Portland actually look like? Is there a connection between queer communities and space? What are the roles of gender identity, race, class and age in these spaces?

\section{Results and Discussion}

We know particularly little about the community dynamics of contemporary queer women, and even less about the consequences for queer women's ties of recent shifts in identity politics and changes in legislation and social attitudes (Brown-Saracino, 2008)

Before I moved to Portland, I used to hear about the how many queer women there were in Portland. The term 'lesbian mecca' was used more than once to describe the city. 
Other than the visible presence of queer women in the city, I was not entirely sure of what this meant. A quick Google search of Portland led me to a 'Queer City Girl Guide' on a popular website. The section on Portland reads:

It's an amazing city and has brought us together in the Queerest of ways. Here, we can be out and proud without fearing discrimination, and the city is not only jam-packed with queer ladies, it's also well-equipped with Queer-positive laws, events, and resources. And yes, every day in this Queer Mecca is like an episode of Portlandia. (Nguyen, 2012)

This sort of commentary is far from uncommon; the popular perception is that Portland is a progressive, queer-friendly city with vast resources and queer people. However, there is rarely a complex analysis of the ways in which queer community is present in the city. I was particularly interested in understanding how these communities operate in relation to place and space. The results are divided in three major sections that attempt to respond to the three research questions posed above. The first part attempts to address questions surrounding what these spaces actually look like: the distinction between public, private, cyber, and temporary spaces, as well as the influence of consumerism and substance abuse in these spaces.. The second section explores the meaning of the lack of queer women's spaces particularly in the context of a growingly accepting socio-political climate. This particular part will address whether queer women think that they have a need for queer women-specific spaces, perceptions of Portland's friendliness towards LGBTQ folks, and an exploration of the potential for new public spaces based on opinions and experiences at the old Egyptian Room. The third section will address the roles of gender identity, race, class and age in these communities and spaces. Through 
this section, I will explore the ways in which gender identity, age and racism play a part in the development of connections amongst queer people in Portland.

\section{What do These Spaces Actually Look Like?}

When asked to draw and describe the spaces that identified queer women locations, a lot of participants were hesitant to draw any places in Portland, particularly permanent public locations. Overall, most participants drew maps of houses, bars and coffee shops, sidewalks in particular streets, parks, and dance parties that happen around the city (See Appendix C). No map exclusively showed public spaces. Even though the maps were mostly unscaled or abstract, these representations were focused primarily on the neighborhoods in which participant lived, which in turn meant that the North East and North areas of the city were more represented than other areas in Portland. Even though many maps were drawn signaling the different quadrants of the city, there was a strong concentration in very particular parts of Portland. Visually, maps \#1 and \#14 show the heavy concentration of public and private spaces that are located in the North and Northeast parts of the city. Also worthy of mention is that most of the public spaces that were represented in participant's maps were not repeated in other people's maps. The most common theme in maps was that private spaces are the center of participant's queer spaces. Most of the maps picture people's own homes as well as other private spaces like their friends' and partners' houses. Another relevant pattern was the presence of the internet as a queer women's space. 
One of the questions that I was interested in addressing when conducting interviews was how do women categorize a queer women's space compared to any other space? Most of the participants talked about these spaces as signifying broadly two things: safety and representation. For most participants, the spaces pictured on the map were spaces in which queer women feel safe and places in which they can see their identities represented in some capacity. For example, right after Janet finished drawing her map, she clarified that she "just did a North/South, East/West map of Portland and my comfort levels by color coding. So the green areas are the places I feel completely comfortable, pink areas are some comfort and orange are not comfortable." (Map \# 11) For her, the most important identifier of a queer women's space is level of comfort and safety. This is crucial in understanding the ways in which queer women, and potentially other marginalized communities, occupy space. When individuals do not see themselves represented in particular spaces, they are less likely to feel safe and less likely to participate in those spaces. Given these answers, it is not surprising that most of the people who were interviewed mentioned their homes and other private spaces like their partner and friends' homes as focus points in their spatial existence.

\section{Public Spaces: Capitalism and Substance Abuse.}

Cities across the country have seen a decline of public queer specific spaces, particularly ones geared towards women. Countless bars in San Francisco, Los Angeles, New York and Portland have closed their doors for a variety of reasons. In Portland, the last queer women's bar closed in 2010 and there has been no known attempt to create 
something similar. While conducting the interviews, many participants asked follow up questions about the kinds of spaces they could draw, arguing that there was technically no queer women specific place in Portland. As they drew, they kept adding public spaces with caveats about their relationship to queer women. Some of these places were places where they felt safe or places that they frequented, others were locations where other queer women were visible, and others were places that were owned or staffed by queeridentified people.

Most of the public spaces that participants mentioned in the interviews and drew in the map were bars. Some participants included the Queer Resource Center at Portland State -University, queer-friendly sex shops, sidewalks, parks, cafes and restaurants. None of these spaces are advertised as queer, which means that these spaces are frequented not because of their inherent queerness, but because of the sense of comfort or visibility that these locations bring to participants. As Browne (2006) warns, however, it is important to rethink the ways in which we conceive of spaces in a hetero/homosexual binary: with the growing acceptance of queer people in North American culture, these distinctions might overlook the complexities of people's identities and spaces.

Something that was rather surprising about the maps and the interviews was that there were very few spaces that were mentioned more than once or twice. Other than In Other Words, the Local Lounge, Crush, dance parties located in different parts of the city, Portland State University and Alberta Street sidewalks, no place was mentioned more than twice. This seems to indicate that public queer women spaces are decentralized: each 
community or individual has particular spaces that they deem as queer, but they are not understood as queer by everyone else. The diversity of these spaces is telling of the diversity of the queer communities in Portland, and the lack of specific spaces. For some participants, however, this meant that most of Portland was safe and accessible. Whether the lack of specific spaces signifies a success or a loss became a question that interviewees grappled with throughout the interviews. Besides these public and private spaces, participants mentioned different types of urban and cyber spaces that exemplify the complexity of urban geographies for some non-hegemonic communities.

The public spaces that participants described in their maps were also highlighted in the interviews as places centered on consumption and substance use. Even though this research is not an analysis of the role of capitalism or consumerism in queer spaces, I was interested in exploring the topic through the participants' eyes. Many of the participants talked about the challenges of accessing public spaces that were modeled to benefit business owners and not their communities. One of the issues that participants raised was that the public spaces that they frequented were operating within a capitalist model of profiting from customers rather than providing a space where community can be created. The second major concern was that most of these places were centered around alcohol consumption or drug use. Participants felt like these two conditions prevented the development of any type of political action, a safe place to organize, or a comfortable place to stay sober. 
Somewhat lacking from most of the maps and comments in the interviews was the presence of community spaces or centers. In reality, Portland does not have many spaces that queer people can access resources or meet other queer people outside the context of alcohol and consumption. Some of the spaces that were mentioned were In Other Words and the Queer Resource Center at Portland State University. Largely missing from the narratives was the Q Center or SMYRC, two major queer community centers. SMYRC provides resources for queer and trans youth, which is one of the reasons why they were probably not mentioned in the interviews. The Q Center, on the other hand, has received criticism for their lack of competency around transgender or race issues. The lack of community centers is apparent and probably due to countless issues like funding and politics.

Some queer women who were interviewed mentioned that they would be interested in seeing an actual community space where there is a potential for interacting with other queer people as well as accessing resources and creating a political base. Heather, for example, thinks that one of the reasons why queer women have moved to the internet and private spaces is because businesses do not align with the politics of many of her friends or community:

I think a lot of the space just takes place on the internet, or in private spaces. Um, because once you start to get into businesses or public spaces, that gets into like the politics of that institution that is driven by like capitalism. And like it's not addressing like intersectional needs of people and so for spaces to be actually safe, they kind of have to exist on the margins or like outside of those public or business spaces. (Heather) 
In Other Words, the feminist bookstore and community center that was mentioned by most people either in their maps or interviews, is the closest thing that queer and trans women have to a space in which they can develop community and not participate in capitalist transactions or substance use. This October, however, they released a statement on their website and other social media platforms stating that they were recruiting a new board and new volunteers, as well as financial help in order to keep their doors open (In Other Words Website, October 11, 2014). Even though none of the participants mentioned that they frequented the space on a regular basis, most of them said that it is a very important space for the feminist and the queer community in Portland. This particular space has been nationally recognized due to the show Portlandia, which has portrayed the bookstore in a satire of the city of Portland. One of the participants was concerned with the way that In Other Words was being shown:

Talk about how In Other Words is mocked on Portlandia, what does that mean for feminism and women? How are we supposed to access these spaces that are being devalued and violently attacked? [...] When you put that much hate, honestly, back into that space, how are we supposed to be legitimized in a real space? That's the only space that I have to not drink [...] The system is setting it up so that we only have these spaces, other than parks that come with their own risks (Michelle)

Michelle is concerned that the only space that is close to being a community center for queer women is being mocked by television producers. Another thing that she mentions is that this is one of the only spaces where people can get together without alcohol being involved. Queer bars have been crucial in the development of queer communities around the country, particularly before the internet allowed people to 
connect across the country, and the political climate became less hostile. Morgan recounts that "there's a really long history of queers going to bars as meet up places and that was sort of like initially because people didn't know where to go, and a lot of people were closeted or underground or didn't want to be out" (Morgan). She also discussed that being queer is hard and that substance use and abuse are ways in which people cope with the realities around them. Michelle, as well as other participants, was concerned with the fact that queer individuals rely on alcohol to meet other people:

Alcohol in general being used by specifically marginalized populations that might have experienced trauma and dealing with developing identities, the promotion of alcohol use in general. They can be bars or portals of violence in a way. The implications of that is that Portland is a drinking town and if our communities are enveloped in alcohol, there is less opportunity for growth and sustainable health practices. (Michelle)

As many participants suggested, the fact that capitalism has enveloped most public spaces is more reason to understand queer geographies as a complexity of yes, public bars and cafes, but also as a network of private, temporary and cyber spaces.

\section{Private Spaces}

As mentioned before, most participants pointed out the importance of private spaces in their maps. Homes were mentioned in almost all of the maps. Others also described the importance of their friends and partner's homes. For example, Heather drew houses in her map (map \#3) that represent her home, her friends, partner and expartner's houses. These spaces were constantly brought up as places that queer women occupy safely. One of the participants, Janet, mentioned that "really the only place that I 
feel extremely comfortable as a queer woman, that I consider a queer women space, is my home." This was not unique for the set of participants in the study. Time and time again, participants drew small pictures of houses all over their maps to represent the importance of non-public space in their lives (See Appendix C, all maps except \#4 and \#8).

Private spaces, however, were not limited solely to the home as a structure. For one of the participants, the space in which she felt the most comfortable and safe was her bedroom. Her map is composed solely of an image of her bed (See Appendix C, map \#7). More than exemplifying a trend in the importance of beds in queer geographies, it brings to light the potential to conceive of these places at different scales and in different forms as valid and relevant to some communities; particularly those who have difficulty appropriating public spaces. Private spaces, then, are crucial in understanding the ways in which queer women relate to urban space and create community.

According to the interviews, these private spaces are crucial in understanding the lives and experiences of queer women in Portland. Overall, participants believed that patriarchy, less access to financial capital, less safety in public spaces, and obviously, the lack of availability of queer public places were some of the reasons why private spaces served as the centers for community building. Back in 1983, in his study of the San Francisco gay scene, Castells argues that the research could not possibly reflect lesbians and their experiences due to their lack power and presence in public spaces. He argues that lesbians are placeless because they behave mainly as women; because they did not 
have 'territorial aspirations' like gay men did. This research seems to suggest that queer women, indeed, rely on private spaces to develop communities. Unlike Castells, however, I argue that private spaces need to be included in the discussion of queer geographies and they need to be understood as part of a larger network of places that queer women occupy. I suggest centering queer women's experiences and, in turn, private spaces, in order to understand their geographies, rather than dismissing them as 'placeless.'

In her research about lesbian living spaces, Elwood described how "in the experience of minority cultures for whom daily life outside the home may be fraught with a wide variety of struggles, home can take on particular significance as a place of belonging" (2000: 4). Elwood's analysis emphasizes the importance of the 'home-place' in lesbian communities but it does not explore how to relate the private scale to other public and cyber spaces. Even though homes were described as the center of queer women's space in the interviews, and Elwood's research emphasizes this claim, it is important to understand the context in which private spaces have become as crucial as they are.

\section{Temporary Spaces}

Another type of spaces that queer women occupy is what I call 'ephemeral queer spaces' which refers to public spaces that are temporarily queered. The implications of the potential of turning any space into a queer space are that any, or most, places can turn into a safer and more visibly queer place. This type of space is best described by the multiple queer-specific nights in different bars. These dance parties are the center of 
night life for queer women in Portland. Even though many participants expressed their concerns with having the focus of a community be bars which operate in capitalist ways and are mostly operated by non-queer business owners, they serve as a center for a certain type of community: a rather young, middle class, and mostly white community.

These ephemeral spaces, however, are not limited to bars or dance parties. Some participants talked about how any space can become queer when there is a recognition and visibility of other queer people. Lila, for example, talked about the ways in which a queer moment and place can be created almost anywhere and at any time:

I don't think it necessarily makes the spaces queer. I think for people who can read queer we can see it, and in a way, we can temporarily transform the spaces that are not queer into queer spaces because of how we are reading people and situations (Lila)

This type of queer space can be refreshing and comforting particularly in locations where queer visibility is minimal. Conceptually, however, this type of space leaves us wondering what happens after queerness has moved through it: is the space at all transformed and is it useful in thinking about the potential of community in different places?

Sidewalks

The built environment also has an effect on the ways in which queer women relate to space. Given Portland's emphasis on neighborhood-living and large number of main streets for particular neighborhoods, the sidewalks are a place that people perceived as queer. Three of the participants mentioned that the sidewalks on Alberta St. were a queer 
space, mostly because they could see visibly queer people, but also because of the way they were built. In the next quote, Michelle describes how the sidewalks on Alberta were queerer than the ones on Mississippi:

Mostly it's just thinking about streets. And oddly there is something about Alberta sidewalk that felt like a queer space to me, more that Mississippi sidewalks maybe because the sidewalks in Alberta are wider. (Michelle)

Michelle mentioned that certain sidewalks are queerer than others but was not particularly sure why. She believed that the width of the streets made them more accessible and perhaps safer than the ones on Mississippi St. All of these spaces are relevant to the ways in which queer women relate to Portland and other queer people. From their homes to bars and sidewalks, queer women are present in most places of the city, negotiating urban space and their identities. Many participants, however, also talked about the importance of the internet as a queer space.

Internet

The internet has changed the ways in which people relate to each other and develop connections with other people both in their place-based communities and at a distance. Spaces like Facebook, Tumblr, Twitter, and Instagram allow for the development of communities through affinities and interest. Since the early 1990s, there has been an interest in the role of the internet in the development of online interest-based communities (O’Riordan, 2005). As mentioned in the literature review, there are still many conversations and discussions around whether virtual communities can be 
classified as 'real' communities. Wellman and Guilia (2002) argue that internet communities share many characteristics with place-based communities: participants develop supportive relationships and ties, they adhere to norms of reciprocity and may enhance social ties that take place in face-to-face interactions.

Most of the participants talked about the importance of technology and the internet as a safer way to meet people and build networks of support or affinity. The internet was usually represented as a placeless box in the middle of the maps. For example, in map \#3, Heather drew a big box representing the internet, while on map \#5 and \#13, Rachel and Karina respectively drew a computer connected to physical spaces and other people. In map \#14, Jessica drew a cloud around the city representing the permanent presence of the internet in queer women's lives. When exploring issues surrounding the internet, some of the interviewees were concerned with the fact that the internet had lessened the need of physical spaces since meeting people was easier on websites like OKCupid. Has the internet replaced the need for places in which queer women can potentially develop communities? Valerie talked about the ways in which dating websites can privatize meeting other people:

I think OKCupid has changed the face of things. I think a lot of queer women, also because of the economy and because they don't have as much money, they meet on OKCupid and go out somewhere like coffee or to each other's houses, really low cost things and hang out. So just in my circle I see, I mean most of my friends are on OKCupid even if they are partnered. (Valerie) 
Participants were torn on whether the internet was an instrument or a hindrance in the creation of queer communities. Most participants believed, however, that it served as a tool that helped queer women meet other people, but that internet communities per se were not the goal. Lila, for example, used a phrase that she had seen as an advertisement for an online dating site: "Get online to get offline." Even though this phrase was specifically used to talk about dating, I think it exemplifies the ways in which queer women relate to the internet: it is a way for people to develop friendships or relationships that can translate into non-cyber spaces. Karina, another participant who uses the internet in order to do outreach for a prominent queer party in Portland, said that "you can't JUST have the internet, it's boring. You want to drink a drink and find someone cute that you've never seen before and talk to them." (Karina)

The internet, then, has the potential to assist in the development of communities. More importantly, however, is that queer women feel like this is a space that they can mostly occupy safely. Virtual spaces offer a cheap and safe way for queer women to connect to each other without depending on temporary dance nights or the availability of public spaces. Cyber spaces have become more visible and frequented, but the research on what the effects that they have on queer communities has been limited. Some research indicates that in less queer-friendly places, the internet has come as a 'lifeline' to LGBTQ people, and has provided a relief from isolation of queer individuals (Friedman, 2007). In Portland, however, it seems like the internet serves as a tool to develop communities that may or may not be present in the 'real' world. Rather than conceiving of the internet as separate from other types of space, this research attempts to understand the ways in 
which cyber spaces serve as a liminal location whose existence facilitates the development of communities, but possibly negates the need for queer-specific public spaces because people have other ways of connecting to other queer individuals. Given the prevalence of the internet on maps, it would not be possible to think about queer communities in Portland without including the internet.

\section{What is the role of queer women-specific public spaces in queer women's lives in the context of an accepting socio-political climate?}

Through this research, participants were able to describe the spaces that they frequent as queer women. The purpose of this section is to better understand what the lack of queer women-specific public spaces means to queer communities in Portland, as well as how Portland's liberal policies and lifestyle have contributed to the existence or not of these spaces. After establishing that there are no queer women specific public spaces in Portland, I was interested in determining what this meant to individuals, and whether they thought that there was a need for a specific space or if they thought that the combination of private, public and cyber spaces was enough. Exploring this particular question is crucial because it allows us to better understand how queer women in Portland relate to space and each other. More importantly, however, it is telling of the state of LGBTQ politics in cities across the United States. Does acceptance and the right to marry negate the need for queer-specific spaces? Not only were participants very divided 
on the issue, everyone thought that it was a complicated question that had no right answer.

Some of the participants, however, felt more comfortable with the idea of not having a specific space. Karina, for example talked about how these particular spaces are obsolete in a place like Portland:

I think because specifically in Portland it would feel kind of an outmoded, it would feel outdated. I definitely don't think it feels outdated in other parts of the country where people are experiencing different forms of oppression on a day-to-day basis. If politics were not working as much in favor of queer rights, I think that those spaces would feel more vital. (Karina)

This quote appears to say that in a place like Portland, with a progressive reputation and seeming acceptance of queer folks, the need for specific spaces has diminished. In other places where there is less acceptance of LGBTQ people, however, queer specific spaces might be more necessary. Other participants quoted different reasons why these spaces might not be useful in providing a safe space for queer people in Portland. Jessica, for example, said that she is wary to suggest that these spaces are necessary:

do I think they are needed? I sometimes do. When we are talking about community events for people to like get together. But for me, there's this hesitancy and a fear of people policing gender and gender presentation (Jessica)

This particular concern was mentioned in many of the interviews: a fear of having queer women spaces that were not inclusive of trans and gender non-conforming individuals. It is important to note that this is gender inclusion was cited as one of the main reasons why 
people are hesitant to talk about queer women-specific spaces in Portland. Particularly due to the large number of trans and people of different genders in the city, these spaces could be seen as outdated and exclusive. Other participants recognized that this could be an issue but still thought that if done properly, in an inclusive way, in the right location, this type of space could be successful. Morgan, who has spent the past 13 years in Portland, thinks that “there's this idea that there are so many queers here, why do we need a queer women's bar? What is that? And also that it's irrelevant, that we've moved past gender-exclusive spaces and that to me is sort of a queer tragedy, like 'oh my god, we're not there, that's not true."' (Morgan)

Morgan thinks that despite the inclusive rhetoric that is prevalent in Portland, queer women still have a need for queer specific spaces. More specifically, a lot of the participants also believed that there is something to be gained from having a space that is not centered on gay men. Heather, for example talked about how she does not want to be in a space that is dominantly masculine, but wants those spaces to be inclusive of her trans and gender non-conforming friends. When talking about gay men specific spaces, many of the participants described an unsafe feeling or discomfort in spaces that were designed for and by gay men. Most importantly, they felt like it was overly sexualized and focused around alcohol. Many participants were interested in visualizing a space beyond bars in which communities can develop a sense of unity. Maya, for example, made a distinction between spaces centered around consumption like bars and cafes, and political spaces: 
I've heard people say that we are aging out of the time that we need out own community spaces. I don't think that's true, I mean maybe like in the business sector, maybe you go get coffee at a coffee shop that is not a gay one and it's going to be alright. I can go there with my girlfriend and it's going to be ok. But I don't think that that applies the same way to like political spaces or sort of like community service work spaces. I think that we need more of that kind of community especially now that we seem to be steering away from having like queer specific businesses (Maya)

\section{Portland}

This particular research focused on Portland primarily because of the perception of it as a leading progressive city in the United States. Some think that the city is ideal for people who are interested in alternative lifestyles, and queer communities are part of that rhetoric. The validity of these arguments goes beyond the scope of this research, but a theme regarding the degree of friendliness and safety for queer people in Portland emerged during the interviews. Many of the participants stated that queer folks seem to have an easier time than in other places that they had lived in, particularly smaller towns. At the same time, many of them were critical of this notion of friendliness and safety. Jessica, for example commented saying that "I think that in Portland and more of these liberal places there's this idea that like we morph into other spaces. And so therefore there's really not a need for queer women only space." (Jessica)

One of the participants, Nora, talked about how Portland is more positive around queer issues even without the existence of queer specific public spaces:

I don't think the lack of public spaces means it's not a mecca for gay women, I can go out and get a girls number almost anywhere I go. And 
it's not because I'm a ten, it's because, you know, people are more sex positive here, they are more flexible with their identities here, and they are more accepting of yours. (Nora)

Morgan agreed with the fact that Portland was safe, but she concluded that it did not mean that specific spaces should exist:

You know that there is this notion that Portland is so progressive and no one is going to give you shit as a dyke at a regular bar; like you're going to go to some hipster bar in North Portland and no one is going to treat you like shit or look at you funny. But that's really different than going to a dyke bar (Morgan)

Many of the participants were significantly more critical of the notion of Portland as a safe haven for queer women and queer folks in general. All of the participants of color mentioned that they did not feel safe in Portland but assumed that this had to do with race and not with queerness. Even two of the white participants said that they felt safe but recognized that it was probably because they were white. Racism will be addressed below, but it is important to mention that the feeling of safety and comfort is deeply influenced by participants' intersecting identities. The rhetoric of acceptance and tolerance in Portland was widely contested by participants. For example, Janet mentioned how she was always told that Portland was a feminist city, accepting of traditionally marginalized communities. In the following quote, however, she describes her feelings towards the city:

I always felt that what was so deceptive is that there is a very implicit form of sexism and patriarchy and homophobia that comes with the idea of people just saying 'oh women's voices are heard and we welcome queers in the community.' I think that the liberalism in Portland, even the queer liberalism in Portland is very surface. (Janet) 
The complexity and diversity of spaces that queer women occupy is telling of the types of communities that inhabit the city. These spaces vary in scale and form: they are private, public, online, and temporary. They also mirror the political and social context in Portland, OR. The lack of specific spaces is intriguing but not new. Queer women's spaces in the country are in decline and exploring whether another space like the E-Room could exist in a different context is an interesting exercise that surfaces the diversity and divisions within the queer communities in Portland. Perhaps the most important part of this process is that participant's maps and interviews served to show queer women's geographies in the city go beyond permanent public spaces based around consumption and alcohol. In the next section, the research will explore participant's ideas and conceptions of community in queer Portland, and how this is related, or not, to the presence of the spaces mentioned in the map.

\section{Ghosts of the Egyptian Room}

The question that opened this section was intended to address the effects of not having queer public spaces in Portland, and what this means in the current socio-political climate. I was interested in finding out about the last place where queer women were the main clientele. Perhaps by better understanding what this space looked like, the reasons for its closure and the ways in which participants related to this place, this research can better recognize why such bars do not exist in Portland anymore. As mentioned previously in the paper, the only queer women specific bar in Portland closed down in 2010. The Egyptian Room was open for 15 years and was located in a large establishment 
on Division St., in the Southeast quadrant of the city. Before it closed, the management of the bar attempted to transform the space into an all-inclusive bar called Weird Bar. This move was not successful and it sealed the end of the bar. Now, the building sits on a highly developed strip on Division filled with fancy restaurants, coffee shops and vintage shops. As the interviews went by, participants kept bringing up the E-Room to exemplify the way in which things have changed in Portland. Maya recalls spending her $21^{\text {st }}$ birthday there, and the importance that the bar had in her coming out process. For these reasons, she decided to include it in her map: "I have the old location of the E Room on this map because it is so hard to forget, like, anytime I go down Division I'm like there's that place, there's a lot of drama energy still lingering around this place. Still feel it." (Maya)

The official reason for the closing down of the bar was never released. Some of the participants, especially those who have been in Portland for a long time, however, had various hypotheses of why the E-Room had closed. The three main speculations of why this space did not survive were: a change in politics moving towards inclusion of trans and gender non-conforming folks; a switch to more specific dance parties; and migration of queer folks to other parts of the city.

Comments like "the E-Room was also very traditional, in its lesbianness and very gender specific in its lesbianness and I think that Portland doesn't really buy that" (Maya) and "something happened were it got a reputation for being old school lesbian and people were really pushing back against that identity at the time," (Morgan) exemplify how the 
politics between 'queer' and 'lesbian' created a separation in the queer communities. The reputation of the E-Room as being an 'old-school' spot, exclusive to cis queer women who mostly identified with a lesbian identity, greatly hindered the bar management's ability to adapt to changing communities and individuals within the city that were attempting to be more inclusive of trans and gender non-conforming people. This transition might also begin to explain the decline of queer women specific spaces around the country.

Another reason cited for the lack of success of this bar was the expansion of dance parties around the city. These events, which often happen once a month in different places around Portland, offer specific alternatives depending on the type of music or party people are interested in attending. With the exception of one event, the Temporary Lesbian Bar, no event is meant to be exclusive for queer women. Valerie, a participant who used to frequent the Egyptian Room, talked about the role of these dance parties in the demise of this bar:

When The E Room was all there was, they were plush. I think it was really grindy, it wasn't a place you necessarily wanted to hang out. But you do what you have to do in desperate times. But after, when there were other options, I see why people chose them. And I miss it, I miss it a lot, I wish there was another space (Valerie)

It appears that these dance parties are more representative of the diversity of queer people in Portland: they are often targeted towards specific communities and tend to be inclusive of trans and gender non-conforming people. 
Another reason cited in the closure of the E-Room was a migration from Southeast Portland to the North and Northeast quadrants of the city. Twenty years ago, when Sy Adler and Johanna Brenner wrote about queer women geographies in Portland, the largest concentration of them was in the Southeast. Now, it appears like younger queer women have settled in the North and Northeast. Some businesses have also tried to adapt to the population change. For example, In Other Words, the feminist bookstore, has also moved from Hawthorne in the Southeast to the North. Participants mentioned that perhaps the E-Room was not successful because people were not willing to go to Division St. anymore. Morgan spoke to this migration: "When I moved to Portland initially, Southeast was like the hot spot; SE was the place where people told me queers lived. Especially women. And now lots of queers are moving to North Portland and NE and that's kind of established" (Morgan). If this was the main reason why the E-Room was not successful, then there is a possibility that another queer women's space could exist and thrive:

I think right now, if there was suddenly a queer women's bar I think it would be enormously successful just because, depending on where it was, if it was in sort of the northeast, more party center, youth centered queer community, it would be very successful. However, would it be a place where I felt comfortable or the other queer women's communities felt comfortable? No. I don't think it would be (Janet)

The Egyptian Room is symbolic of a changing political climate in Portland and perhaps in other places around the country. The transition from a 'lesbian' to a 'queer' identity, the importance of trans issues for the community, and a migration of queers and 
spaces to North and Northeast Portland are ways in which the demise of this bar is telling of a changing community. Whether another place that is specifically geared towards queer women will ever emerge remains to be seen, but it appears that Portland maintains its reputation as a 'lesbian mecca' regardless of the presence of these spaces.

One of the most interesting questions surrounding this research is whether the decline in queer spaces has affected people's sense of community with other LGBTQ people. Based on the experience of the E-Room, as well as participants' assessments of Portland, it appears that queer women have been able to create and/or maintain networks of support and interest with other queer people. Many of them, however, still believe that they would like to have a public space that they could frequent as queer people. The question of whether queer women in Portland need a public space does not have a simple answer. Based on the interviews, it appears that a bar like the E-Room is no longer needed in the city. These results seem to mirror Brown-Saracino's research in Ithaca, NY (2011). Rather than depending on specific spaces and tight networks of support and social interactions; the lesbian community has evolved into what the author calls an 'ambient community.' This does not mean, however, that queer women do not want a public space; it just does not seem to be a necessity to maintain communities. For some more marginalized groups within the LGBTQ scene, such as people of color or trans individuals, a space of that nature might be more critical than for cisgender white women. In the next section, I will explore how other intersecting identities affect the development of queer communities in Portland. 


\section{What are the roles of gender identity, race, class and age in queer communities and spaces?}

One of the questions that were at the center of my interest in queer women's spaces was whether the political, cultural and social acceptance of primarily gay and lesbians was affecting the need for community and community spaces. At the beginning of the interview process, I asked participants to describe the queer women's community in Portland from their point of view. Most participants responded that they did not think that such a community existed; rather it appeared that there was a queer women's scene that was comprised of many different groups of friends and acquaintances. In a similar research project, Brown-Saracino concludes that in Ithaca, there is a challenge to the traditional notions of a uniform 'lesbian community' due to some of the reasons mentioned above: changing political climate and differences between community members (2011).

I don't think there's a singular community, I think Portland is small enough that you'll like run into people you know the longer you are here. It feels like in that sense it is singular, like people are queer and they live in Portland and they know each other. But in terms of like solidarity or working together or creating spaces together, that's more just like personal friend groups (Heather)

The example of Portland seems to support the work of Ghaziani (2011), Gamson (1995) and Brown-Saracino (2011) indicating that identity-based queer communities are evolving and perhaps disappearing. Participants mentioned that they do not see a sense of unity between queer people living in the city. To the contrary, these communities are broadly divided in terms of age, acceptance of different gender identities, by race, and by 
neighborhood. If Portland's 'progressiveness' and acceptance of queer folks is expanding across the country, are we going to see a reduction of queer communities across the United States? Participants seemed wary of this prospect, but were also aware that sharing identities is not reason enough to develop communities.

Jessica, who identifies with belonging to a queer and trans people of color community, talked about how even within that community, values are often conflicting, preventing the development of meaningful connections:

I feel like for queer folks of color, in my experience, in Portland, I think that there is a strong need to sort of cling to any bit of community that we have. But then the challenge in that is the realization that maybe we don't all have the same values. Maybe we do on the surface but not genuinely. Simply sharing identities is not enough. (Jessica)

This quote exemplifies how the specific marginalization of people of color might cause queer people of color to maintain a sense of community with each other, even if it is based on identities and not interests or political goals. Other participants were also aware that sharing identities is not enough to develop connections with other people. Valerie talked about race and class playing a part in developing friendships and connections with other people: "I feel like as with all intersecting identities, class and race play a huge role in who we're friends with. I would say especially in the Northwest. [...] So I would say people really stick to their class lines and those communities" (Valerie). Along with class and race, gender identity and age are categories that often define queer communities. According to all participants, these categories are crucial in understanding the different communities that exist in Portland, as well as the reasons why they are fractured. 
These comments follow recent literature that claims that sexual identity has become a less relevant basis for community (Podmore, 2006; Rothblum, 2010; BrownSaracino, 2011). For example, Brown-Saracino determined that "narrow identities do not necessarily organize queer women's experience of community. In Ithaca, the inverse is at least partially true: community dynamics turn attention away from sexual difference to other facets of self and, in turn, encourage alternate nodes of connection" (2011: 25). In a recent study comparing queer women and their heterosexual sisters, Rothblum (2010) found that increasingly, these individuals form groups in which sexuality is not the main commonality between them. Rothblum found that as long as lesbian and bisexual women felt supported in other aspects of their lives, the need for a queer women's specific community was diminished. The author calls this 'de-centered' lesbianism: sexuality is no longer the focus of queer women's communities (2010). Compared to previous research on lesbian communities in the 1980s and 1990s, Rothblum's study seems to indicate that common identity has become less important in the structuring of queer women's identity. These findings also seem to support Ghaziani's (2011) argument that a 'post-gay' era is characterized by both assimilation into the mainstream and internal fracturing within the LGBTQ communities. In the next few pages, I will explore the ways in which other identities such as gender identity, race, and age affect the development of communities in Portland, Oregon. 
Inclusion of Trans and Gender Non-Conforming People

The discussions emerging about gender-segregated spaces and the inclusion of trans and gender non-conforming individuals is crucial in understanding current queer communities and the spaces that they occupy. Soon after beginning the interviews, I realized that most participants were reluctant to identify with a queer women's community. Many of them specified that a lot of their friends, partners and community members did not identify as women. A lot of times, when talking about spaces, they would suggest that none of the spaces were particularly for queer women, but could be for queer people in general. This trend is, arguably, a crucial factor in queer communities. Spaces that identify as women or men specific are often seen as exclusive. Heather, for example, was reluctant to identify any space as women-specific because "if you start calling something a queer women's space that could be exclusive of, that could be seen as exclusive of trans people and that's not the space I want to be in" (Heather). In a similar vein, Lisa talked about why she thinks people do not want to identify spaces as women-specific:

I think people would be hesitant to say I have a "women's" space because that might be super problematic, and all of a sudden you could feel like you are with the wrong group of people with the wrong politics (Lisa)

Most of the participants were troubled by identifying gender-segregated spaces because they did not want to be exclusive of trans and gender non-conforming people in their communities. The politics around gender-segregated spaces has shifted partially due to the history of trans exclusion. One of the most decisive opinions on why queer 
women spaces do not exist in Portland was that queer communities cannot continue to have exclusive spaces when large portions of their friends do not identify as women.

Another theme that emerged in the interviews was that Portland is a relatively safer place for people who do not identify with the gender binary or who are trans. According to Valerie, Portland is unique compared to other cities in the country because it is a safer environment for trans and gender non-conforming people:

I think there is a ton of gender variant folks here. And yeah, I think that Portland is, compared to the rest of the country, a relatively safe place to come out. I don't think there's anywhere that is THAT safe for trans and gender variant people (Valerie)

This perception of Portland was mostly shared by participants, even though a few people mentioned that there is a greater acceptance of trans and gender non-conforming folks who are perceived as more masculine. Jessica commented that "I think that probably more folks are accepting of folks who identify more like transmasculine or masculine of center as supposed to transwomen" (Jessica). According to the interviews, gender variance is relatively accepted in some queer communities in the city. This does not mean, however, that Portland is a safe space for trans folks. Lucy, who identifies as a trans woman, said that she feels comfortable in Portland compared to other places, even though she continues to encounter some harassment in the workplace.

The greater visibility of trans and gender non-conforming people in Portland, the media and the country seems to have led to a greater reluctance to create and frequent gender-specific spaces. Even though a lot more research is needed in order to determine 
the cause of the demise of queer women-specific spaces, this research seems to suggest that gender identity has played a role in moving particular communities away from segregated spaces into others that feel inclusive of people of all genders. This shift seems to be a recent occurrence even in Portland. Some participants talked about how there is a difference between younger and older queer women in regards to their acceptance of trans and gender variant people.

Age in Queer Communities

Like in many communities, age influences the ways in which we relate to each other and form connections with other people. Queer communities in Portland are not an exception. Some participants mentioned that older queer women had different interests and were not as involved with the events around town. Lisa, who is 52, commented on how she gets treated when she goes out to events or parties around Portland. During the interview, she recounted a time when she went to one of the queer parties: "I actually had like somebody thank me, and I'm pretty sure they were thanking me for being an older dyke showing up at the night. Which felt really like, you know, being objectified" (Lisa). This quote exemplifies how older queer women experience spaces designated for younger people.

Segregation through age is not uncommon, but according to participants, it also has to do with the politics around gender identity. One of the most common comments regarding age in queer communities was that there was a difference of acceptance of trans 
and gender non-conforming people between younger and older generations. Although this was not the case with the people that I interviewed, a lot of the participants mentioned that older women, who might identify with a 'lesbian' identity as supposed as a 'queer' one, were less likely to be accepting of trans and gender non-conforming individuals. Valerie, who is 33 and has done work organizing around trans issues, mentioned that she sees a generational change in the acceptance of these issues:

I think that watching the stuff around trans activism has really made me see that this is very generational to me. The resistance that some of the older folks are having, the language that is not maybe appropriate. And honoring people's self-identities, the resistance that I'm hearing and seeing is from older folks. And I feel like the younger generation is more inclusive of people in general and there is less of a sectioning off (Valerie).

Another thing that exemplifies the difference between generations and communities was the terminology used to describe their identity. Many participants mentioned that there is a distinction between people who identify with 'lesbian' and people who identify with 'queer.' Many participants talked about a shift in the language in the 1990s that equated the term 'lesbian' with separatist feminism and 'queer' as more flexible and accepting of different genders and trans people. Drucker (2011) argues that the rise of neoliberalism has given rise to 'queers' as a rejection of mainstream gay and lesbian movements that have integration into the capitalist socio-economic relations as the center of their concerns. People who identify as queer, according to Drucker, are more likely to be lower income and resist assimilation into mainstream society. 
Race

While generational differences are important in understanding the current state of the 'queer scene' in Portland and a transition to an acceptance of gender variance, race appears to be the most impactful identity in the development of queer communities. Race has largely been missing from literature that addresses queer women's experiences (Moore, 2011), so I was particularly interested in understanding how participants conceptualized race in queer communities in Portland. Every participant mentioned that queer communities were drastically divided by race, and that the mainstream queer scene was not welcoming or accepting of people of color. As mentioned in the introduction, Portland has had a history of exclusion and discrimination of people of color, particularly the African American community. The processes by which discrimination has occurred continue to be present in the city, and have aided in the displacement of black communities out of the city. According to participants, these circumstances seem to be reproduced in queer communities. The two main topics that emerged in the interviews are: Portland is not as safe of a place for queer people of color compared to white queers, and queer communities in Portland are racist and not accepting of queer people of color.

Research on queer communities of color, particularly queer women of color, is limited and, to my knowledge, has not focused on their relationship to space. In Invisible Families, Moore (2011) discusses how black queer families are more likely to live in black neighborhoods and center their black identities, than to live amongst white queer people and prioritize their queerness. In her ethnography, she discussed how these 
families occupy a variety of public and private spaces, such as their homes, their friends' houses, school functions and community events (Moore, 2011). These spaces are particular to their age group (mostly over 20), their familial relationships, and their race. During the interviews, women of color explained that they experienced the world as racialized queer individuals; their queerness was always mediated by their race, and they had to negotiate their experiences in public spaces.

For example, Janet, a mixed-race queer woman in her twenties, talked about how she felt safer as a queer person than a person of color:

I'll feel comfortable being queer but I won't feel comfortable being nonwhite. Or I'll be with queer women of color specifically. I think there are a lot of very legitimate racial frustrations with the white queer community so there is not, there is almost this complete division between the queer community in general and queer people of color. And it's not there there's not people who occupy both spaces comfortably, I just haven't seen it very much. (Janet)

Lila, a 23 year old Vietnamese woman, wonders why some of the dance parties are so divided in terms of race:

I don't know, it's like why is it that Slo Jams is a predominantly QTPoC [queer and trans people of color] space and then you go to Ms. and it's predominantly a white space. Like why does that happen? Does it have to do with money? Does it have to do with access? Does it have to do with the fact that you have to pay to go to these events? Where they are located? Also though, who's organizing these events and what's their agenda? (Lila)

Some white participants mentioned that they felt safe and welcome in the queer scene and in Portland in general, but that they were aware that this could be different if 
they were not white. Heather mentioned how she had felt mostly safe in the city as a queer woman, until she started dating a person of color, when she felt a lot more threatened and observed by other queer and non-queer people. So when talking about the biggest challenges to the queer community, she said "I think the need would be to address racism in the community, I think that's the most pressing because to me, as a queer person in Portland, a queer white person in Portland, I feel safe, I feel included, I feel like I can get jobs, I don't feel discriminated against." (Heather)

In the interviews, some participants mentioned that the only public space that is targeted to queer women of color (and other LGBTQ people of color in general) is a once-a-month dance party in a bar in Northeast Portland. This particular space is organized by queer people of color and the DJs tend to play R\&B. This event does not address racism or issues particular to the community, it has just become the only queer space where people of color are the majority. The other spaces that the participants of color mentioned were private homes.

Participants of color talked about racism in Portland as one of the main sources of division within queer communities. Most people of color that I interviewed did not feel comfortable in queer dance parties or other queer spaces because they did not feel safe or felt like the people in the space had a critical analysis of race. Discrimination and race issues, however, are not only present at an individual level. To the contrary, instances of racism in the queer community happen at all different levels. For example, Jessica talked 
about her experiences at dance parties, as well as an incident that happened a few years ago in Portland in one of the most prominent gay bars:

Just like hearing stories of my QPoC friends going to these dance parties and being completely fetishized by white women and un-consensually touched, constantly. Like it's definitely happened to me in those spaces, by other queer white women. And just even just with incidents have happened in the community where this prominent leather bar bringing racist blackface drag queen to their establishment and how the broader queer community went to bat and were really defending the Eagle for doing this. And I think that speaks volumes and I think that that's reflective of how queer folks of color, and how I've experienced, the dominant queer white community in Portland (Jessica).

In January, 2013, the Eagle, a leather bar in North Portland, announced a performance by a blackface drag queen whose act mocks black women by enacting racist stereotypes (Rook, 2013). The announcement elicited a strong response by queer people of color in Portland and around the country. Eventually, the bar cancelled the performance and apologized for the pain that the announcement had caused. The Facebook event elicited hundreds of responses, including powerful accounts of what this means for black women in Portland. For example, Leila Hofstein said:

This is a hurt unique to my roots and experience as a severely marginalized person in American culture. It's a violent slap in the face, a Tour de Force of every micro aggression I experience every single day, rolled up in a nice shiny package for the world to see. And then people laugh. They laugh at a mockery of my life. They laugh with those who do not see several folds of comedic irony: with every bully, with every older white man who still sees me as property in some way, they laugh with the skinheads who jumped me in middle school, they laugh with my oppressors. So there you are. This isn't a tongue-in-cheek burlesque 
display. That sort of thing can't exist yet, at least not the way Shirley is doing it. (Hofstein in Rook, 2013).

The pain caused by the event is telling of the experiences of queer people of color, particularly black people, in Portland. One of the participants said that "race is an issue in Portland, because it is an issue everywhere" (Lila). Queer or trans shared identities do not negate other forms of oppression like race or ethnicity. The Portland queer scene has not possibility of political action within queer communities.

In this section, I was interested in understanding how intersecting identities such as age, race, and gender identity, were experienced in queer communities and queer spaces in Portland. The queer communities in the city seem to be fractured by particularly by age and race. The division in terms of age, according to participants, might be related to the degree of acceptance of trans and gender non-conforming people by older queer women. All participants suggested, also, that institutional racism and Portland's whiteness makes it particularly hard for queer people of color to be part of other queer communities. With growing social and political acceptance, queer people do not feel an imminent need to form connections with other queer people who might not share their values or other identities (Brown-Saracino, 2011). These other identities seem to be reflected not only in the communities that people choose, but also in the spaces that people inhabit. There were very few spaces that women of color mentioned that they could occupy in the city while feeling safe in all of their identities. 


\section{Conclusion}

This research has tried to determine queer women's relationship to space, particularly in the context of a changing political climate and a growing fracturing in the queer community. In this section, I will summarize the results and then analyze this paper in the context of the literature. Finally, I will pose some questions that remain unanswered but that require future attention. Participants talked about the types of places that they occupy: spaces at different scales, some that are ephemeral, some that are virtual, but none that are public and permanent. The need for specific public spaces was largely debated during the interviews as many respondents thought that queer people did not need them anymore, while others thought that the communities were not ready to lose them. The main reason cited for not needing these spaces was that Portland was a safe and queer-friendly city. Many, however, believed that negotiating other identities, such as race and gender identity, made Portland an unsafe place. This growing fracturing within queer communities also seems to be a cause for the disappearance of space. These issues were discussed in the interviews and drawn in the maps. The implications of this research are vast both in queer studies, urban studies, and geography.

The main characteristics of a queer women's space, according to participants, are a feeling of safety or comfort in their identities and a sense of representation in the space. Even though Portland is a queer-friendly city, there are not a lot of public spaces in which queer women can develop community. Private spaces are crucial in these women's lives: providing feeling of safety and a place to create networks with friends 
and acquaintances. Queer women also occupy other spaces like bars and cafes, even if none of them are specifically designed or run by other queer women. The only spaces that are geared towards queer and trans women are temporary dance parties in different bars and restaurant around Portland. Finally, participants talked about the internet as a space in which they can create community and use as a tool to meet other queer women. All of these spaces constitute a network of locations where participants felt like they could be recognized in their identities.

Perhaps one of the most debated and controversial items discussed in the interviews was whether the changing times, acceptance and political climate were making queer public spaces unnecessary. Some participants argued that since there is a growing visibility of queer people, particularly in a 'progressive' city like Portland, these spaces are no longer as important as they used to be. Some people feel like there is no longer a desire to create queer-specific spaces because people can access all urban spaces and feel safe. Without a need to develop community, to develop a network of people who have the same sexual orientation, these spaces have slowly disappeared. The decline of queer specific spaces has been documented across North America both by popular media and recent academic work (Podmore, 2006; Nash, 2013; Brown, 2013; Doan and Higgins, 2011). Gay neighborhoods and bars, once the center of gay social, economic and political life, have begun disappearing due to a changing generation more interested in assimilation (Nash, 2013) and socio-economic processes like gentrification (Doan and Higgins, 2011). When talking about the disappearance of the Egyptian Room, participants talked about the same processes that the literature proposed as causes of the 
decline of spaces: a migration to a different part of the city, a changing generation, and an increase in fracturing of the community.

Initially, I was interested in understanding the ways in which the availability or lack of spaces affected the development of community. When discussing this, participants were ambivalent about the effects of place in making connections with other people. Rather than saying that the lack of spaces prevented the creation of community, they were concerned with other issues that plague queer communities. Some of these concerns were based on differences within the queer community, and concerns with creating spaces that are accessible and inclusive of different gender identities and presentations. Many participants believe that there is a perception that spaces and queer communities are no longer relevant due to the growing acceptance of queer and trans people in mainstream media and politics. The relationship between space, particularly public space, and community does not seem to be as relevant as some of the issues raised by participants.

Other participants, however, were nostalgic about queer specific bars or parties because they were symbolic of a time when they were coming out and in need to meet and connect with other queer people. But their concerns with the disappearances of these spaces were not only based on nostalgia, they were also based on a feeling that the mainstream acceptance of queer people is not enough to deem queer communities unnecessary because this acceptance is only based on the premise that LGBTQ folks will adhere to hegemonic notions of family and citizenship (Duggan, 2002; Ward, 2008). The 
question of whether queer specific spaces are still necessary is one that needs further exploration. The literature has not particularly addressed the consequences of the disappearance of space, and how this will affect the development of communities and political action.

After discussing the effects of the disappearance of queer spaces and whether people feel like those spaces are needed, I was interested in understanding how intersecting identities play a role in queer communities in Portland. The generational difference between younger and older queer women might account for the decline of queer women-specific spaces around the country. Gender-segregated spaces seem to be disappearing due to concerns around inclusion of trans and gender non-conforming people. While discussing the potential for a queer women's space in Portland, interviewees were wary of identifying something as 'women' because of the implications of having gender-specific spaces. As the awareness and consciousness of these issues has grown, so has the reluctance to develop or access gender-segregated spaces. This, perhaps, is one of the most important pieces to recognizing the decline of women spaces around the country. This issue, however, is not the only factor that affects the development of spaces. When discussing the possibility of a queer space that was inclusive of trans and gender non-conforming people, participants talked about other concerns like the focus on alcohol and consumption, racism, and the growing irrelevance of these spaces. 
The history of racism in Portland and Oregon continues to be crucial in understanding race relations in the city, as well as the socio-economic forces that have caused gentrification and development in the city (Gibson, 2007). Participants who did not identify as white, as well as many of the white participants, were blatant about the racism in the queer community. Many believe that it is very difficult to create community or to be in queer spaces that promote fetishizing people of color or that simply erase the experiences of black and brown people in the city. Unless white queer communities in Portland recognize and address racism in this context, it is not very likely that queer people of color as a whole will feel safe accessing spaces created for and by white queer people. As we have seen in the limited literature on queer communities of color, non-white queer individuals might prefer to participate in communities of color and navigate their queer identity, than accessing queer communities as non-white people (Moore, 2011). If issues of inclusion of both people of color and trans and gender nonconforming people are not addressed, it is not likely that a queer women, or even queer, space will be successful or relevant in Portland.

In 1983, Castells wrote that "men have sought to dominate, and one expression of this domination has been spatial. [...] Women have rarely had these territorial aspirations: their world attaches more importance to relationships and their networks are ones of solidarity and affection" (140). For these reasons, The City and the Grassroots was not meant to speak to queer women's experiences with space; because they were 
'placeless.' This research seems to agree with Castells given the importance that participants placed on private spaces. His study, however, completely neglects queer women's experiences and suggests that urban studies or geography have no place in investigating private spaces. What participants speak to is a complexity of networks and spaces, rather than an agreement that women only exist in a private sphere. Instead of questioning the reasons why queer women exist in certain spaces and not others, Castells is only interested in gay men's appropriation of the Castro neighborhood in San Francisco. Future literature needs to adapt questions about the relationship between queer women and space in order to create a framework that can make sense of queer women's geographies. Through a small number of participants, this research begins to understand the ways in which queer women relate to space and its meaning when understood in the context of assimilation and acceptance.

At the same time, this paper seeks to engage with literature that explores the seeming demise of queer spaces around the country. Existing research suggests that queer spaces are in decline due to changing attitudes both within and outside the queer community (Ghaziani, 2011; Nash, 2013). Participants agreed that changing attitudes have transformed the ways in which LGBTQ people relate to space and other communities. However, this research is unique in its emphasis on inclusion, particularly in relation to trans and gender non-conforming individuals. Gender-segregated spaces in Portland raise a concern that queer communities are transphobic. The literature also neglects to explore the role of race and racism in the development of queer communities and spaces. In this paper, I attempted to better understand the experiences of queer 
women of color and some of the barriers that they face when developing networks with people who do not share their identities.

Beyond the necessity of spaces, this research also brings up questions about the future of queer movements and queer communities as mainstream society becomes more and more accepting. With the development and growing access to the internet, people no longer require permanent public spaces to create and maintain relationships with other queer women. In a provocative title, Gamson (1995) asks whether identity movements must self-destruct. The answer to this question is still unclear, but it seems like as queerness becomes more accepted in the mainstream, many LGBTQ people have less of a desire or need to develop tight networks of support. In Portland, queer women seem to have developed what Brown-Saracino (2008) describes as an "ambient community": a more informal web of relationships without formalized institutions or resources.

This begs several questions that I pose to future researchers surrounding the relationship between queer women and space: do these communities and community spaces only arise when a group of people feel unsafe and threatened? Or is there not enough social and economic capital in order to create these spaces? In order to answer these questions, more research in necessary particularly on the needs and desires of queer women in other areas of the country. Because of the ways in which racism and transphobia affects particular communities, separate research needs to gather the experiences of marginalized communities within the LGBTQ scenes. In the following section, I will explore the theoretical frameworks that could be used to better understand 
queer women's geographies; as well as the consequences of the mapping method and participant's awareness of the spaces that they occupy. 


\section{Chapter III: Spatial Frameworks and Queer Mapping}

\section{Introduction}

The third chapter of this paper will try to address two different questions: How do we reenvision spatial frameworks in order to understand the spatial patterns of queer women and other marginalized communities? And what role can mapping and representations of space play in the ways in which queer women occupy space? The previous chapter intended to exemplify the ways in which queer women in Portland articulate their presence in the city, occupy spaces and develop communities. This research, however, is also interested in exploring better ways of understanding queer women's geographies based on their accounts of utilizing space. As covered in the previous chapter, the spaces that queer women occupy encompass private locations, temporary public spaces, the internet and random streets and sidewalks. How, then, do we map these spaces in order to better understand queer women?

Given the diversity of shape and scale of the spaces that these communities occupy, understanding their geographies and the ways in which they relate to space can be challenging. Planners and most geographers (perhaps with the exception of emotional geographers) tend to be concerned solely with public spaces; spaces that are designed for the public, rather than private or accidental places. Since this community lacks identifiable permanent public spaces, we need a framework that is able to incorporate private, temporary and cyber spaces. Even though everyone occupies a variety of spaces that are often not mappable, marginalized communities are often neglected because they 
do not use or occupy space in the same ways as more hegemonic groups. In this chapter, I will explore the how we can think about space in an inclusive way, and how we can use mapping to transform the spaces that we occupy. The first part will talk about space and how queer women's geographies can inform ideas of space. The second part will discuss the possibilities of mapping the spaces that people occupy as a reframing and rethinking of urban space.

\section{Spatial Frameworks}

\section{Background}

The concept of space has been largely debated by geographers and scientists. In Uneven Development, Smith (2008) traces the development of the concept throughout history. He claims that earlier societies did not make a distinction between space and matter, and it was only through time that space became abstracted. The concept then evolved to Newtonian conceptualizations that made a distinction between absolute and relative space. This relative space included social space which was contained within the physical, absolute space. This dualism continued to exist through the positivist era. Positivism holds that society, like the physical science and the physical world, operates according to general laws that can be measured and replicated. Ideas of space, however, began to include the concept that social and physical spaces interacted with each other. After the 1960s, and later aided by the poststructuralist turn, critical geographers have made an attempt to rethink these spaces as dialectical and inseparable from each other. According to Smith, geography has only begun to dismantle this dualism. He argues that the 
“conception of the 'production of space' is meant to provide a means of taking the next step and enabling us to demonstrate rather than simply assert the unity of space and society [...]. This production of space also implies the production of the meaning, concepts, and consciousness of space which are inseparably linked to its physical production" (Smith, 2008: 106-107). This production of space is directly referring to Lefebvre's theories.

In a lecture called "Space as a Key Word," David Harvey argued that there are three different types of space: absolute, relative, and relational. For Harvey, absolute involves the physical environment, while relative incorporates the ways in which space and individuals exist in relation to each other. The concept of relative space, however, does not allow us to conceive of it beyond the social processes which produce it. The relational view holds that "processes do not occur in space but define their own spatial frame. The concept of space is embedded in, or internal to process" (Harvey, 2004: 4). This framing of space is what Smith argued is necessary in order to understand the process in which space is produced. In the lecture, Harvey suggests that this relational conceptualization is the only way that we can begin to understand notions of identity. Until recently, issues of identity had been mostly neglected in geographical thought. In order to understand issues of gender, race, and sexuality, the dualistic perceptions of space are useless unless our goals are to focus on examining residential patterns or consumption locales. I suggest that we can also utilize Lefebvre's theories of space in order to address issues of identity within cities, and in order to identify opportunities for change. 
Many have written about the relationship between social phenomena and space, but it was Lefebvre who developed a framework that described space as a dialectical and relevant part of social everyday life. He was interested in understanding space in relationship to the everyday life of its inhabitants and the ways in which they participate in the production and transformation of space. By utilizing Lefebvre's framework of the production of space, its different dialectic components, and the emphasis on daily experiences, it is possible to better understand the ways in which queer women, in particular, interact with the urban in order to create and appropriate urban space. Rescaling the production of space will also allow research to focus on the 'everyday' life of queer women, as well as begin to understand the emancipatory possibilities of the right to the city for populations that are often deemed as 'placeless' or 'unmappable' (Castells, 1983; Peace, 2001).

\section{Lefebvre}

Lefebvre's theories have been crucial in reframing space and the ways in which it is produced. His theories challenged positivist perceptions of concrete and relative space. For Lefebvre, space was produced by a dialectical relationship between 'perceived space,' 'conceived space' and 'lived space.' Perceived space (also referred to as spatial practice) can be described as the objective physical space which people encounter on their day to day actions. Conceived Space (also called representations of space) refers to the abstractions of space: the mental constructions of places (e.g, maps, plans, et cetera). Finally, the relationship between these two concepts leads to lived space (also called 
representational space or spaces of representation). Lived space refers to the ways in which individuals actually experience a location. In Marxian terms, this last concept can be thought of as the use value of a particular space. These different types of spaces are in a dialectical relationship, and our experiences with them affect how we interpret and understand other representations. Space, in this context, needs to be understood as a process in which our perceptions, conceptions, and experiences are informing each other to constantly change and produce urban space.

Perhaps the biggest issue with Lefebvre's concepts of everyday life, the production of space and the right to the city is that they are conceptually rich but lack a practical element. Lefebvre suggests that all individuals who are affected by a certain phenomenon should take part in the decision-making process that affects it. If decisions made across the globe affect the urban scale in which we are citadins (word used to describe urban inhabitants in contrast to citizens, which denotes a governmental recognition) should we have the right to influence these processes? As Purcell (2002) asks, if land-tenure legislation changed in Oaxaca, Mexico, would people in Los Angeles have the right to make decision surrounding that process because of the ways in which it will affect migration into the city? How do we determine the ways in which to distribute power in these circumstances? These theoretical issues require interpretation and an implementation that is difficult if not impossible. Lefebvre, also, does not explain how marginalized individuals can experience space compared to people who have more privilege or power. That being said, Lefebvre has been widely used to explain phenomena in cities across the world. 
Henri Lefebvre was concerned with understanding the everyday life of urban settings. According to Merrifield, Lefebvre believed that everyday life was a site for meaningful resistance, "the inevitable starting point for the realization of the possible" (Lefebvre in Merrifield, 2002: 79). Merrifield continues to argue that, since institutions do not occupy the street, this level is particularly ripe for contestation that can spread to higher levels of analysis. Before the streets, however, I suggest that we can rescale the analysis of space production to the body and to the home: spaces that are even less controlled and occupied by institutions such as the state or capitalist corporations. Particularly for marginalized communities, private spaces can be crucial in developing communities. Lefebvre's analysis, however, is not specific about how to use this concept at different scales.

According to Purcell, the right to the city "reframes the arena of decision-making in cities: it reorients decision-making away from the state and toward the production of urban space" (2002: 101). In this context, I argue that research should not exclusively focus on large-scale production and appropriation of space. Lefebvre's interest in daily urban occurrences is crucial for focusing on populations who do not have the option of participating in the established processes of space production and appropriation. There are ways in which we can begin to conceptualize how certain populations can participate in the creation and appropriation of urban space. As Harvey mentioned in his lecture, conceiving space as the concrete or relative is not useful in understanding issues of identity. The historical and structural elements that contribute to someone's identity in relation to space can be better approached with a framework such as Lefebvre's. Lefebvre 
believed that the "urban considered an intermediate level (M) which mediates the social totality as a whole. The urban is related to the level of the large social order $(\mathrm{G})$ (the state and state-bound knowledge, the capitalist world economy), on the one hand, and the contradictory level of everyday life $(\mathrm{P})$, the daily rounds of lived experience, on the other" (Kipfer, et al. 2012: 119). I argue that in order to better understand issues of class, gender, race and sexuality as lived experiences, we need to address them at level $\mathrm{P}$ - the level of everyday life (2012).

\section{Place and Queer Women's Spaces}

Scholars continue to use Lefebvre to describe the ways in which denizens participate in urban processes. Many use his theories as a starting point to understand individuals' engagement with space. Unfortunately, the practicality of the concept of the 'right to the city' is limited, particularly for groups that have been historically marginalized. Groups that do not have access to the public spatial fabric of the city (e.g., queer women) are forced to conceive of space in a different manner: one that uses different scales and a diversity of spaces that are neglected by Lefebvre and other geographers. Feminist geographer Doreen Massey, for example, describes place as a "bundle" of space-time trajectories drawn together by individuals through cognitive and emotional processes $(2005,140)$. Massey is particularly interested in understanding place as the focal point in which a set of political, social, environmental and geographical relations meet. This particular framework allows us to understand queer women's geographies as the node of a set of personal and social relations. According to Massey, 
all of these spaces are negotiated between all who are involved. Massey's framework is useful because it allows different actors to interact in order to create nodes of place, regardless of its relationship to the local or global contexts. Even if queer women do not have the same power to transform urban space that a planner has, the places that they occupy are negotiated and existent. Using Massey's theory, then, queer women have spaces and they are as (un)mappable as any other group. At the same time, this theory allow us to conceive space and place across scales; Massey seems to indicate that both public and private spaces are the consequences of these relations, making homes and other private spaces relevant in understanding queer women.

The spaces that interviewees mentioned were a combination of places of different shapes and scales. One of the most interesting aspects of the maps and the interviews, at a theoretical level, is that all of the spaces at different scales were pictured in the same two-dimensional map: there was not an explicit distinction between public, temporary, private or cyber spaces in any of the maps. When Lefebvre talked about the right to the city, he was not necessarily referring to private spaces, but rescaling his theories can also be useful in recognizing emancipatory possibilities. In a Marxian sense, the private is crucial in understanding social reproduction. Women have often been relegated to the private sphere, which tends to include the home and other spaces that are crucial in the maintenance of social life. For Lefebvre, producing urban space "necessarily involves reproducing the social relations that are bound up in it" (Purcell, 2002). If Lefebvre was aware that the reproduction of social relations was crucial in the production of space, we need to take into account the ways in which women could lead the efforts in 
(re)producing the home space. Even Lefebvre himself emphasized how everyday life is disproportionately a women's responsibility (Kipfer, et al., 2012). Hence, these forms of down-scaling the 'right to the city' could prove useful in the development of a movement that accounts for identity.

Queer Women's Scales

Using both Lefebvre's production of space and right to the city, as well as Massey's ideas on place, we can begin to conceptualize a spatial framework that is useful in understanding particular marginalized communities' geographies. By looking at the maps that queer women drew of the spaces that they occupy on their everyday life, we can see how rescaling the concepts of production of space can be useful in understanding their geographies. Most of the maps include houses; private spaces that were often described as the center of their queer identity and community building. These spaces are often neglected by Lefebvre and other geographers because they do not seem to be political. Queer women, however, mentioned that they were the center of their community building. Particularly for queer and trans people of color, who do not see themselves represented, safe, or respected in public spaces, private scales are crucial in the creation of social and political alliances. By further exploring Lefebvre's different scales and emphasizing the P level, we can begin to make sense of private spaces as locations where queer women can develop social and political capital as their own 'right to the city.' 
One of the participants, Joanne (See map \#7) was interested in portraying the place that she considers the most queer and most safe: her bedroom. Following the descaling process previously mentioned, we can expand the understanding of more specific spaces such as bedrooms, beds or bodies. Particularly when addressing the spaces which women can produce and access, considering the body as a scale of social reproduction and political potential seems appropriate (Martson, 2000). Women, for example have a history of fighting for the right to control decisions that affect their bodies directly. A few examples of these kinds of issues are the right to reproductive choices, the right to control the ways in which women enact their gender, and the right to manage their body image. The production of the corporeal space might not seem relevant in greater social movements that attempt to affect urban space, but it is a crucial beginning for a population that has been denied these basic rights. If we conceptualize the production of representations of the body by women as an act of resistance, this population might be more ready and able to participate in other scales. Women should have the right to participate in the production of their bodies as more than mere objects, as well as have the right to make the decisions that affect them directly.

Time and time again, the maps show the ways in which queer women occupy and create space in Portland. Most maps appear similar, usually divided in the quadrants, portraying some public locations, some private homes, and other temporary or cyber spaces. One particular map, however, rates areas of the city, as well as specific spaces as comfortable or uncomfortable. In Map \#11, Janet demonstrates how, regardless of Lefebvre's ideas of the 'right to the city,' the production and occupation of space are 
limited for those who do not adhere to traditional identities. As a queer woman of color, she does not feel like she is able to occupy public spaces comfortably or safely.

Particularly in the more wealthy areas of the city (North West and South West), Janet does not find spaces where she can be in her identities.

Lefebvre and Massey have contributed to the literature of space and its connection to social relations. In this particular context, Lefebvre allows us to understand the importance of day-to-day activities in the production and appropriation of urban space. The lived experiences of queer women in Portland are useful in understanding how inhabitants experience space in an urban setting. In this particular case, queer women's accounts demand a framework that includes scales that are often erased in urban and geographical studies. The consequences of including these spaces (e.g., the home and the body) in any framework are related to the understanding that marginalized communities utilize space in ways that are different to normative communities. Massey describes how place is created by the links in social, political and economic relationships. In this case, these two frameworks allow us to better understand and validate the actual locations that queer women relate to. Even though this is useful in providing a nuanced understanding of a particular group in a particular space, its political consequences are still unaddressed. How, then, do queer women create urban space? And what are the consequences for community building and potential political action? 


\section{Production of Space and Mapping}

For Lefebvre, inhabitants of a place should be entitled to both participation in the production and appropriation of urban space. When talking about participation, he argues that individuals should have a say on the decision-making processes that produce urban space. Decisions regarding the production of such space are often reserved for those in power: corporations, the state, planners, and developers. How, then, do we engage marginalized populations in the creation of all of these forms of space? How do we create cities that respond to the needs, wants, and desires of the most vulnerable groups? If space is produced by the interactions of conceived, perceived, and lived space, we need to engage individuals in the production of all of these spaces. Since these are all in a process, once one begins to change, the other ones will too. Perceived space is the most difficult to transform in resemblance to the needs and wants of citadins given the rather concrete nature of it. However, by challenging the normative conceived spaces, individuals might be capable of changing the ways in which they interact with other components of the dialectic. In this section, I argue that the practice of mapping particular spaces is crucial in the creation of urban space due to the importance of conceived space in Lefebvre's dialectic.

In the process of mapping particular spaces that are relevant on the daily lives of queer women, many participants were surprised to realize at the lack of spaces that they felt were available to them in their identities. At the same time, most of them mentioned how they had never thought about the specific spaces that they consider being for queer 
women in Portland. This process is important in identifying locations where people feel safe and also recognize the potential in the development of community. The method of asking participants to draw maps regarding the spaces where they see themselves was not meant to be used to develop a larger scaled map indicating queer public spaces or neighborhoods with high concentrations of queer individuals. Instead, this exercise had two consequences: it showed how queer women occupy a diversity of spaces, perhaps forcing us to move beyond Cartesian understandings of space in order to understand their patterns; and it allowed participants to rethink the spaces that they inhabit. In the following section, I will speak to the mapping method and its potential to be transformative.

Maps and Power

Traditionally, maps are a function of power; supposedly created through scientific and objective methods. J.B Harley proposes, however, that there is a need for a new epistemological approach to mapping. Drawing from Foucault and Derrida, Harley critiques and traces the history of cartography and the assumption that maps are "a mirror of nature" that utilize technology (i.e., Geographical Information Systems or GIS) in order to develop an "accurate" depiction of space (1989). Harley emphasizes how "social structures are often disguised beneath an abstract, instrumental space, or incarcerated in the coordinates of computer mapping" (1989: 5). Issues of class, race, sexuality, and power are present in maps but are disguised by a curtain of science and systematical production of knowledge. Beyond the deconstruction of the production of maps, Harley 
suggests analyzing the purposes of these maps in order to better understand what Lefebvre called representations of spaces. Many of these maps are funded by the state, the Church or other hegemonic institutions. Maps are "crucial to the maintenance of state power - to its boundaries, to its commerce, to its internal administration, to control of populations, and to its military strength" (1989: 12). Maps promote hegemonic forms of perceiving the world; maps are power-filled representations of space that indicate us how to interact with our surroundings.

Within the context of the city, maps have been "used in attempts to tame the urban labyrinth, and to represent its spaces as 'legible' and 'knowable'... transform its messy incoherence's into a fixed graphic representation” (Pinder 1996:407).

Representations of space, such as maps, are used to create a very particular understanding of space, determined by those who have the tools to represent spaces. Maps, however, can serve an unlimited number of purposes and can be used as tools of community empowerment, artistic expression, resistance, et cetera. Providing alternative forms of representing space can be subversive and powerful. Moving beyond the scientific, geometrical, and appropriate-scale techniques that are put forth by normative cartographers, we can explore very distinct modes of depicting and representing space that are useful both to a specific community as well as for the general population that is made invisible by traditional mapping. In "Subverting Cartography; the situationists and maps of the city," Pinder proposes a "tactical, artistic and political use of urban maps and mapping” $(411,1993)$. These maps can be a source of power and understanding for marginalized groups. Often times, the act of representing space is denied to the bodies 
that interact with said space. Non-normative groups' ability to "map" their space is linked to their difficulty with claiming space and carving space.

Anthropologists and critical geographers have used map-making projects to address issues of gender in cities. William Leap, who has done extensive work on gay men's relationship to space in Washington, D.C., conducted interviews in which he asked respondents to draw a "gay map of Washington" and the ways in which the destruction of some bars had affected the city (Leap, 2009). By asking participants to draw a map, he was able to develop an interview and a conversation that was significant to his research questions. When attempting to understand space and place, neither maps nor interviews alone would have been able to inform his study. Edelman has followed a similar technique for exploring transgender spaces in Washington, D.C. (Edelman, 2012). Mapping has been used to better understand the ways in which certain communities experience space, but little has been written about the effects of mapping on participants or conceptions of space.

Mapping Possibilities for Queer Women: Production of Space

The method for this project, an interview with a map-making activity, is an example of ways that certain groups, queer women particularly, can begin to reclaim urban spaces by representing them in a map that directly speaks to them. This does not mean, however, that the act of mapping itself has produced or allowed queer women to appropriate space. It does mean, however, that participants are changing the narrative that 
they are placeless and unmappable. All individuals have conceptions of what they regard as meaningful urban space. If we follow Lefebvre's ideas around the production of space, conceived space is how place tends to be represented and understood. As addressed before, conceived space is referred to as those abstractions of what space is supposed to be like according to those who have the tools to conceptualize it. Maps, graphs and other 'scientific' depictions of space are examples of the representations of space that are commonly utilized to produce it. However, if individuals move away from conceptions of space that focus on technological tools (e.g., GIS), they can promote ideal spaces that best serve their needs. Cartographic representations of space by residents, even if they challenge proper scaling and 'accurate' descriptions of physical space, can allow individuals to understand the types of space that are needed and preferred by the most marginalized groups in society. These abstractions of urban settings can be crucial in transforming the ways people interact with the perceived space thus creating new lived spaces. Hence, participating in the process of producing space can be started as an exploration of people's conceived space, and the possibilities of transforming it to an ideal structure.

In the context of this research, queer women who participated in the study were able to rethink the ways in which they occupy space around the city. As participants were asked to draw or conceptualize these locations, they were shocked by how their geographies were impacted by their identities in the sense that they did not feel safe or represented in many public spaces. Even though many mentioned how Portland was a safer and queer friendly city, participants still felt like there were no spaces in which they 
could be present in their identities. Even though this research was not designed to determine the effects of the process of mapping, if we follow Lefebvre's logic, changing the ways in which we represent space directly affects the ways in which we experience space as well. Future research regarding mapping spaces for underrepresented communities would benefit from following up the interviews with questions regarding the process and the ways in which it can affect how the participants perceive and occupy urban space.

Mapping Possibilities for Queer Women: Appropriation of Space

For Lefebvre, all citadins are entitled to production of urban space. Purcell describes appropriation as the "right of inhabitants to physically access, occupy, and use urban space" (2002: 103). This right not only involves using space that already exists, but it also includes the right to produce space that meets the needs of its residents. Once individuals begin to engage with conceptions of space and the production of urban settings that are relevant to them, the appropriation of space will become easier to achieve. Appropriating urban space is difficult for particular populations due to the inherent inequalities in the availability and accessibility of cities. Individuals who have difficulty in accessing capital are less likely to have the means to participate in these forms of appropriation, particularly if the spaces do not represent the cities that individuals want to inhabit. Issues of visibility can also prove challenging in incorporating individuals into a movement. Some are at greater risk of being targeted by 
the police or other regulatory bodies. As Uitermark, Nicholls and Loopmans remind us, cities are both incubators of social movements and of social control (2012). This makes any type of appropriation difficult for groups that do not fall in the normative conceptions of citizenship.

The appropriation of space is one of the rights that Lefebvre suggests that citadeins should have in relation to cities. All individuals who fall outside the realm of power have to maintain a balance between appropriation and safety. There are particular groups that are more at risk of repercussion due to their visibility. Women, for example, are significantly less likely to appropriate public urban space due to issues like socialization and threats of violence. For most of American history, women have been discouraged from being present in public spaces. The distinction between public and private spaces continues to be a constant in women's lives. Even though women are now more likely to be involved in the public discourse than they have been in the past, there are many challenges to women's occupation of space. Women continue to be discouraged from accessing public locations by themselves at certain times of the day. This does not mean, however, that Lefebvre's theoretical framework is not useful in understanding women's experiences. In fact, even though Lefebvre described men and women in essentialist terms, many feminists have used his framework to understand the experiences of women in space because he understood that the sphere (and space) of social reproduction was largely a women's burden (Kipfer, et al, 2012). 
Other groups are also at a particular risk when attempting to appropriate space. The history of racism in the United States puts African American men at risk from incarceration if suspected of criminal activity. Other groups are also at greater risk for policing from the state. Latinos, regardless of ethnic background, are at risk of being profiled as undocumented immigrants. Examples of raids, unlawful detentions, and other forms of discrimination and policing in urban spaces are common in the United States. These challenges are apparent when comparing the interviews people of color and white people; most of the people of color did not feel like they were welcome in most places in the city. Queer people, particularly gender non-conforming individuals, are also at risk of threats of violence to their persons. Expecting participation in the appropriation of public space by many of these individuals neglects inequalities in the ways in which we are able to exist in public. For some of the groups above, visibility is not safe. Some could argue that this visibility is particularly radical when attempting to produce space. It is important, however, to recognize the limits of these conceptions. Lefebvre would agree that individual actions are crucial in transforming the ways in which we produce space. However, we have to be cautious in expecting at-risk populations to expose themselves in order to respond to these forms of participation.

Particularly for queer people of color, appropriating urban space is not a safe or even plausible option. In map \# 8, Lila created a Venn diagram to show the little spaces that are available to queer women of color and queer folks of color in general. This map shows how the spaces that people of color occupy do not align with white spaces, and only remotely overlap with queer women and women's spaces. Appropriating space for 
communities of color, queer or not, is challenging in a city like Portland. In the interview with Janet, who color coded her map to show degrees of safety, she mentioned that there were spaces where she felt comfortable being queer, but not being a person of color. How, then, are queer people of color supposed to appropriate space in the ways in which Lefebvre talks about? Both participation and appropriation are crucial in the development of spaces that are relevant to the most vulnerable populations. However, the ways in which they have been used to address social movements or their emancipatory possibilities might not be the most relevant in addressing the needs of women, queer individuals, and people of color unless we reduce the scale of analysis and production.

The appropriation of existing urban space, for reasons previously mentioned, is not a possible option for some of the participants. Using previously produced space that is intended for those who have the most power, visibility and representation is a dangerous enterprise. The fact that queer women choose to identify themselves more with private spaces, spaces designed and produced by themselves, or the internet, shows that they are more active in the production of space than in the appropriation of space. During the interviews, some participants explained, particularly white interviewees, that they frequented non-queer spaces, in a way utilizing spaces that they were not designed for them. However, there is a distinction between using spaces that are not designed for a group and the actual reclaiming or appropriation of a place that can serve the needs of a particular group of people. Queer women of color, however, were less likely to mention 
their comfort or feeling of belonging in spaces that were not meant for them. This sense of belonging was restricted to particular spaces such as the home and the internet. While

Lefebvre's theories are useful in understanding how people interact with space, without rescaling or having a critical analysis of gender and race, they are irrelevant in understanding how marginalized communities experience space.

\section{Conclusion}

Queer women have a particular relationship to urban space in the sense that they do not have specific locations where their sexual or gender identities are validated. The theoretical spatial explanations that Lefebvre and Massey put forward are rich and relevant in understanding certain spatial patterns of certain populations. Lefebvre's focus on the everyday lives of people who inhabit the city, the dialectical production of space and the appropriation of space are the beginning for a framework that addresses gender, sexuality and race. This is not, however, enough to conceive of the diversity of spaces in the same map because Lefebvre focuses his theories on public spaces. Massey's ideas, however, allow for an understanding of the importance of scale and power in the creation of a place. How, then, do we conceive of private spaces, temporary spaces and the internet in the same map while recognizing the ways in which power operates within these spaces? How do we include issues of racism and transphobia in these frameworks to better understand issues that affect the LGBTQ communities? 
An ideal spatial framework for queer women, then, is one that includes a variety of spaces such as private homes, some bars and cafes, some community spaces such as In Other Words, temporary spaces such as dance parties or particular moments with other queer people, and the internet. This framework would conceive all of these spaces, maybe not as equal, but as a negotiation of different forms of occupying and producing space. This framework centers the experiences of queer women, or of any marginalized community, by allowing their everyday lives to dictate what their maps and their spaces look like. This framework could serve as a way to understand the geographies of certain marginalized communities. 


\section{Chapter IV: Conclusion and Future Work}

Both of these chapters have tried to develop an analysis of queer women's spaces in Portland, OR. The main issues addressed have to do with the types of spaces that queer women themselves consider to be safe and comfortable in their identities, as well as places in which they see themselves represented. Following the literature, it is not surprising that Portland does not have specific public spaces geared towards queer women. Due to a lack of economic capital and a history of exclusion from gay spaces, lesbian or queer women spaces have never been as visible as gay men ones. For these reasons, queer women have been deemed placeless or unmappable. In an academic context, there has been an interest in 'finding' queer women (See Brown, 2007) while the media is concerned with the fact that lesbian bars are disappearing from American landscapes. Both of these endeavors are valid ways of understanding a group of people who have become more visible in the past decade, but have lost spaces that have been considered the center of their communities.

Queer women public spaces, in reality, where never as widespread as gay men spaces, and queer women never had the financial capital to occupy neighborhoods in the same ways as their male counterparts. Issues of safety in public spaces might have also affected the desire of queer women to create public spaces. It is undeniable that issues of inclusivity also have an effect on the spaces that a supposed community occupies. At least in Portland, both issues surrounding gender identity (and the inclusion of trans women, transmen and gender non-conforming people) and race make the development of 
community difficult. The lack of a unified community might also be responsible for the lack of queer women specific spaces. I argue, however, that the focus on public spaces and their importance in validating queer women's experiences has been exaggerated. Even though bars served as a center where people could meet and perhaps interact in a safe manner, they have always coexisted with other spaces that are arguably more important such as homes. As the interviews and maps showed, private spaces are crucial for this particular group. Queer women have always occupied space, it is just not the space that researchers, planners and governments take into account.

We only need one glance at the maps drawn by participants to realize that there is a variety of spaces that queer women utilize to be themselves or create community. Homes and other private spaces are important both at an individual and at community level. However, this distinction is not only between private and public spaces; other types of spaces are also relevant in the lives of queer women in Portland. Temporary public spaces like dance parties are categorically different from public spaces because they do not provide a place where people can go whenever they desire, they are only there for a few hours per month. This temporality can also be seen in moments and places where there is queer visibility and recognition. Lastly, the internet has become a crucial tool in developing communities and in finding resources across the city. The internet allows for other more tangible spaces to exist, but it also serves as a space where people can be safe in voicing their opinions or being queer. All of these spaces cannot be mapped in regular Cartesian forms without a critical understanding of space. 
Even though many people have theorized space and its meaning, few frameworks allow us to understand the spatial patterns of queer women in Portland. I argue that rather than thinking about queer women as placeless or underground, we need to develop a multi-dimensional, multi-scale framework for understanding spaces for marginalized communities. Populations within the LGBTQ community that are more marginalized than gays and lesbians need an even more complex understanding on the reasons why public spaces are not available or meant for them, while recognizing that they still occupy spaces, whatever they look like. Queer geographies go beyond bars, cafes, parties, and community centers. This research was able to demonstrate the complexity of spaces as well as the ways in which they contribute or deter the development of community. At the same time, it is a beginning inquiry on spatial frameworks that could contribute to a better understanding of queer women's spatial patterns.

It is also important to recognize the importance of allowing participants to develop their own maps and their own stories within this research. Following Lefebvre's concepts of the production of space, we can better understand the ways in which personal representations of space can have an effect on the experienced space for queer participants. In the future, similar research could benefit from following up with participants about the effects of mapping on the ways in which they conceive of spaces that they occupy. It is clear that changing how we think of these spaces is not enough in creating an equitable and accessible city where more marginalized communities feel safe, but it is a first step in acknowledging the importance of different types of spaces in the urban fabric. 
This research contributes to literature on queer geographies, studies of queer communities around the United States, and on literature linking identity and space. This research, however, is just the beginning of an exploration of marginalized communities in space and maps. As mentioned in the last paragraph, this research could benefit from follow up questions regarding the consequences of mapping. Also, further research specifically try to understand the ways in which queer women of color or trans women experience and conceive of space in comparison to their white or cisgender counterparts. In the context of spatial frameworks, research that attempts to map or plan cities for those who are most marginalized could begin to recognize the variety of spaces that people occupy in relation to the most privileged groups. 


\section{Bibliography}

Adler, S., \& Brenner, J. (1992). Gender and Space: Lesbians and Gay Men in the City. International Journal of Urban and Regional Research, 16, 24-34.

Aldrich, R. (2004). Homosexuality and the city: an historical overview. Urban Studies, 41(9), 1719-1737.

Barnhart, E. (1975). Friends, lovers in a lesbian counterculture community. In GlazerMalbin (Ed.), Old Family/New Family: Interpersonal Relationships (pp. 90-115). New York, NY: Van Nostrand.

Bell, D., \& Binnie, J. (2004). Authenticating queer space: citizenship, urbanism and governance. Urban Studies, 41(9), 1807-1820.

Bérubé, A. (2010). Coming Out Under Fire: The History of Gay Men and Women in World War II. Chapell Hill, NC: University of North Carolina Press.

Brown, M. (2013). Gender and sexuality II: There goes the gayborhood? Progress in Human Geography, 38(3), 457-465.

Browne, K. (2007) ."Lesbian geographies,” Social and Cultural Geography, 8 (1).

Brown, M., \& Knopp, L. (2008). Queering the Map : The Productive Tensions of Colliding Epistemologies, 98, 40-58.

Browne, K. (2005). Snowball sampling: using social networks to research nonheterosexual women. International Journal of Social Research Methodology, 8(1), $47-60$.

Browne, K. (2006). Challenging Queer Geographies. Antipode, 38(5), 885-893.

Browne, K. (2009). Womyn's separatist spaces: rethinking spaces of difference and exclusion. Transactions of the Institute of British Geographers, 34(4), 541-556.

Brown-Saracino, J. (2011). From the Lesbian Ghetto to Ambient Community: The Perceived Costs and Benefits of Integration for Community, 58(3), 361-388.

Butler, J. (1990). Gender Trouble: Feminism and the ubversion of Identity. London: Routledge. 
Casey, M. (2004). De-dyking Queer Space(s): Heterosexual Female Visibility in Gay and Lesbian Spaces. Sexualities, 7(4), 446-461.

Castells, M. (1987). The City and the Grassroots. Berkeley, CA: University of California Press.

Crenshaw, K. (1991). Mapping the margins: Intersectionality, identity politics, and violence against women of color. Stanford Law Review, 43(6), 1241-1299.

DeFilippis, J. and Saegert, S.(Eds.) (2008). The Community Development Reader. New York, NY: Routledge.

Doan, P. L., \& Higgins, H. (2011). The Demise of Queer Space? Resurgent Gentrification and the Assimilation of LGBT Neighborhoods." Journal of Planning Education and Research, 31(1), 6-25.

Dolance, S. (2010). “A Whole Stadium Full”: Lesbian community at women's national basketball association games. Journal of Sex Research, 42(1), 74-83.

Driskell, R. B., \& Lyon, L. (2002). Are Virtual Communities True Communities? Examining the Environments and Elements of Community. City and Community, 1(4), 373-390.

Drucker, P. (2011). The Fracturing of LGBT Identities under Neoliberal Capitalism. Historical Materialism, 19(4), 3-32.

Duggan, L. (2002). The New Homonormativity: The Sexual Politics of Neoliberalism. In R. Castronovo and D.D. Nelson (Eds), Materializing Democracy: Toward a Revitalized Cultural Politics. Durham, NC: Duke University Press.

Edelman, E. A. (2012). Articulating Bodies in Tapestries of Space: Mapping Ethnographies of Trans Social and Political Coalitions in Washington, DC. American University.

Eder, D., Staggenboard, S., \& Sudderth, L. (1995). The National Women's Music Festival: Collective Identity and Diversity in a Lesbian-Feminist Community. Journal of Contemporary Ethnography, 23(4), 485-515.

Elwood, S. A. (2000). Lesbian Living Spaces. Journal of Lesbian Studies, 4(1), 11-27. 
Eves, a. (2004). Queer Theory, Butch/Femme Identities and Lesbian Space. Sexualities, 7(4), 480-496.

Florida, R. (2003). Cities and the Creative Class, (March), 3-19.

Friedman, E. (2007). Lesbians in (cyber)space: the politics of the internet in Latin American on- and off-line communities. Media, Culture \& Society. 29(5).

Gamson, J. (1995). Must Identity Movements Self-Destruct? A Queer Dilemma. Social Problems, 42(3), 390-407.

Gamson, J., \& Moon, D. (2004). The Sociology of Sexualities: Queer and Beyond. Annual Review of Sociology, 30(1), 47-64.

Ghaziani, A. (2011). Post-Gay Collective Identity Construction. Social Problems, 58(1), 99-125.

Gibson, K. J. (2007). Bleeding Albina: A History of Disinvestment, 1940 - 2000. Transforming Anthropology, 15(1), 3-25.

Greenberg Raanan, M., \& Shoval, N. (2014). Mental maps compared to actual spatial behavior using GPS data: A new method for investigating segregation in cities. Cities, 36, 28-40.

Harley, J. (1989). Deconstructing the Map. Cartographica, Vol. 26 No. 2. 1-20.

Harvey, D. (2004, May). "Space as a Keyword," Paper presented at Marx and Philosophy Conference. Institute of Education, London.

Hammond, B. (September 30, 2009). In a changing world, Portland remains overwhelmingly white. The Oregonian. Retrieved March 11, 2011.

Hill Collins, P. (2000). Black Feminist Tought: Knowledge, Consciousness and the Politics of Empowerment. Vasa. New York, NY: Routledge.

Hill Collins, P. (2010). The New Politics of Community. American Sociological Review, 75(7), 7-30.

Jacobs, J. (1961). The Death and Life of Great American Cities. New York: Random House. 
Jurjevich, J. and G. Schrock (2012). "Is Portland Really the Place Where Young People Go To Retire? Migration Patterns of Portland's Young and College-Educated, 19802010" Portland State University.

Kipfer, S., P. Saberi, and T. Wieditz. (2012). "Henri Lefebvre: Debates and Controversies," Progress in Human Geography 37(1).

Kitchin, R. (1994). Cognitive maps: What are they and why study them? Journal of Environmental Psychology, 1-19.

Knopp, L. (1998). Gentrification and Gay Neighborhood Formation in New Orleans. In A. Guckman \& B. Reed (Eds.), Homo Economics: Capitalism, Community, and Lesbian and Gay Life. New York, NY: Routledge.

Martson, S. (2000). The social construction of scale, Progress in Human Geography 24 (2).

Martson, S. and N. Smith (2001). States, scales and households: Limits to scale thinking? A response to Brenner. Progress in Human Geography 25 (4).

Massey, D. (2004). Space, Place and Gender. Minneapolis: University of Minnesota Press.

Massey, D. (2005). For space. Thousand Oaks, CA: Sag.

McDowell, L. (1999). Gender, Identity and Space: Understanding Feminist Geographies. Minneapolis: Universtity of Minnesota Press.

Merrifield, A. Metromarxism. New York: Routlege

Moore, M. (2011). Invisible Families: Gay Identities, Relationships, and Motherhood among Black Women. Berkeley, CA: University of California Press.

Nash, C. J. (2013). The age of the "post-mo"? Toronto's gay Village and a new generation. Geoforum, 49, 243-252.

Nguyen, A. (2012, March 5). “Queer Girl City Guide: Portland, Oregon” in Autostraddle (http://www.autostraddle.com/alex-nguyen-city-guide-portland-oregon-133237/) Retrieved October 19, 2014).

Nieckarz, P. (2005). Community in Cyber Space?: The Role of the Internet in Facilitating and Maintaining a Community of Live Music Collecting and Trading. City and Community, 4(4). 
O’Rioirdan, K. (2005). From Usenet To Gaydar: A Comment On Queer Online Community. SIGGROUP Bulletin, 25(2), 28-32.

Oswin, N. (2008). Critical geographies and the uses of sexuality: deconstructing queer space. Progress in Human Geography, 32(1), 89-103.

Parker, S. (2004). Urban Theory and the Urban Experience. NewYork, NY: Routledge.

Peace, R. (2001). Producing Lesbians: Canonical Properties. In Pleasure Zones: Bodies, Cities and Spaces. Syracuse, NY: Syracuse University Press.

Pierce, J., Martin, D. G., \& Murphy, J. T. (2011). Relational place-making: the networked politics of place. Transactions of the Institute of British Geographers, 36(1), 54-70.

Pinder, D. (1996). Suvberting Cartography: the situationists and maps of the city. Environment and Planning A, 28(3), 405-427.

Podmore, J. a. (2006). Gone "underground"? Lesbian visibility and the consolidation of queer space in Montréal. Social \& Cultural Geography, 7(4).

Polletta, F., \& Jasper, J. M. (2001). Collective Identity and Social Movments. Annual Review of Sociology, 27, 283-305.

Poplin, D. E. 1979. Communities: A Survey of Theories and Methods of Research. New York: Macmillan

Prichep, D. (Writer). (2014, August 27). "The disappearance of lesbian bars may signal change.” [Radio broadcast episode]. In Marketplace. St. Paul, MN: American Public Media.

Purcell, M. (2002). Excavating Lefebvre: The right to the city and its urban politics of the inhabitant, GeoJournal 58 (2).

Quilley, S. (1995). Manchester's "village in the city": the gay vernacular in a postindstrial landscape of power. Transgressions: A Jounal of Urban Exploration, 1(1).

Reymers, K. (2002). Identity and the internet: A symbolic interactionist perspective oncomputer-mediated social networks. Paper presented at the Association of Internet Researchers Annual Conference, Maastricht, The Netherlands

Reed, C. (2013). Imminent Domain: Queer Space in the Built Environment. Art Journal, 55(4), 64-70. 
Ren, Y., Krut, R., \& Kiesler, S. (2007). Applying Common Identity and Bond Theory to Desgn of Online Communities. Organization Studies, 28.

Rook, E. (February 1, 2013). "Portland Eagle cancels Shirley Q. Liquor show following outcry." $P Q$ Monthly.

Rothblum, E. (2010). Where is the "Women"s Community?' Voices of Lesbian, Bisexual, and Queer Women and Heterosexual Sisters. Feminism \& Psychology, 20(4), 454-472.

Rothblum, E., Balsam, K., \& Mickey, R. (2004). Brothers and Sisters of lesbians, gay men, and bisexuals as a demographic comparison group: An innovative research methodology to examine social change. The Journal of Applied Behavioral Science, 40, 283-301.

Rothenberg, T. (1995). And she told two friends: lesbians creating urban social space. In D. Bell \& G. Valentine (Eds.), Mappng Desire: Geographies of Sexualities. London: Routledge.

Skeggs, B., Moran, L., Tyrer, P., \& Binnie, J. (2004). Queer as Folk : producing the real of urban space. Urban Studies, 41(9), 1839-1856.

Slagle, A. (1995). In defense of Queer Nation: From identity politics to a politics of difference. Western Journal of Communication, 59, 85-102.

Smith, N. (2008). Uneven development: Nature, capital, and the production of space. Vasa. Athens, GA: University of Georgia Press.

Taylor, V., \& Rupp, L. (1993). Women' s Culture and Lesbian Feminist Activism: A Reconsideration of Cultural Feminism. Signs, 19(1), 32-61.

Uitermark, J.,W. Nicholls, and M. Loopmans. (2012). "Cities and Social Movements: Theorizing Beyond the Right to the City," Environment and Planning A 44 (11).

Valentine, G., \& Skelton, T. (2003). Finding Oneself, Losing Oneself: The Lesbian and Gay 'Scene' as a Paradoxical Space. International Journal of Urban and Regional Research, 27(4), 849-866.

Ward, J. (2008). Respectably Queer: Diversity Culture in LGBT Activist Organizations. Nashville, TN: Vanderbilt University Press.

Wellman, B., and Guilia, M. (1999). "Net Surfers Don't Ride Alone: Virtual Communities as Communities" in B. Wellman (ed.), Networks in the Global Village, pp. 331-336. Boulder, CO: Westview. 
West, C., \& Zimmerman, D. H. (2009). Accounting for Doing Gender. Gender \& Society, 23(1), 112-122.

Wilkinson, K. P. 1991. The Community in Rural America. New York: Greenwood Press

Willson, Kate. (2014, August 14). “Trangender at 10,” Willamette Weekly. Retrieved October 17, 2014. 


\section{Appendix A: Interview Guide}

1. Please draw a map of what you consider to be queer women's spaces in Portland. These spaces can be public, private, abstract or temporary. These can be drawn in whatever capacity you conceptualize them.

2. Please describe the spaces on your map

3. What is your age?

4. What is your race/ethnicity?

5. How would you describe your gender identity?

6. How would you describe your sexual identity?

a. (Probe) Have you always identified as lesbian/queer/bisexual/etc?

7. Do you present your gender as more feminine or masculine or somewhere in between?

8. What denotes a “queer women's space (i.e presence, visibility, safety, et cetera)?

9. How long have you been in Portland?

a. (If applicable) Where did you live before?

10. Would you say that you have actively pursued a queer women's community?

a. (Probe if yes) Have you been able to find it?

b. (Probe if yes) Would you say you used particular spaces to find this community?

c. (Probe if no) Why?

11. Is developing a queer women's community important to you?

a. Why?

12. What are the challenges of developing a queer women's community?

13. Do you think there is a singular community or scene in Portland?

14. Would you describe the queer women's community as existing and thriving?

a. (Probe if yes) Do you think this community is inclusive in terms of gender and sexuality identity?

b. (Probe if yes) Do you think this community is inclusive in terms of race?

c. (Probe if yes) Do you think this community is inclusive in terms of age?

d. (Probe if no) What do you think are the challenges to the community?

15. Do you feel included or excluded from the queer women's community in Portland

a. Can you a specific example of inclusion/exclusion?

16. Are there communities other than the queer women's community that you are a part of in Portland? (e.g. with feminists, gay men, family, et cetera)?

a. (Probe if yes) Is your identity as queer (or other identity) important in the development of other communities?

17. Is your identity important in the development of a queer women's community?

18. Do you think that there are particular spaces in the city that promote the development of a queer women's community?

a. (Probe if yes) Do you think these spaces are important for the community?

i. Do you frequent these spaces? 
19. How do you think a community is maintained? Particularly different than through spaces.

20. How do you think these spaces compare to gay men's spaces?

21. Do you frequent queer men's spaces?

a. (Probe if yes) What are these spaces?

22. Why do you think there are not more queer women-specific spaces in Portland?

23. Do you think a queer women-specific space would be successful in Portland?

24. What do you think has been the role of technology or the internet in the development or maintenance of community? 
Appendix B: Sample Table

\begin{tabular}{|c|c|c|c|c|}
\hline $\begin{array}{c}\text { Participant } \\
\text { (by map } \\
\text { number) }\end{array}$ & Age & Race/Ethnicity & $\begin{array}{c}\text { Sexual } \\
\text { Identification } \\
\text { and/or Gender } \\
\text { Identification }\end{array}$ & $\begin{array}{c}\text { Time in } \\
\text { Portland }\end{array}$ \\
\hline L & 52 & White & Queer & 16 years \\
\hline N & 31 & White & Bisexual/Poly & 1 year \\
\hline H & 24 & White & Queer & 7 years \\
\hline M & 25 & White & Gay/Queer & 3 years \\
\hline R & 25 & White & Bisexual & 20 years \\
\hline M & 25 & White & Gender Queer & 7 years \\
\hline J & 23 & Black & Pansexual & 3 years \\
\hline L & 23 & Vietnamese & Queer & 1 year \\
\hline V & 33 & White & Queer & 13 years \\
\hline L & 44 & White & Trans/Queer & 1 year \\
\hline J & 28 & Mixed & Queer & 6 years \\
\hline M & 35 & White & Queer & 13 years \\
\hline K & 42 & White & Lesbian/Queer & 10 years \\
\hline J & 33 & Southeast Asian & Queer & 2 years \\
\hline R & 26 & Latina & Queer & 3 years \\
\hline
\end{tabular}


Appendix C: Maps

Map\# 1

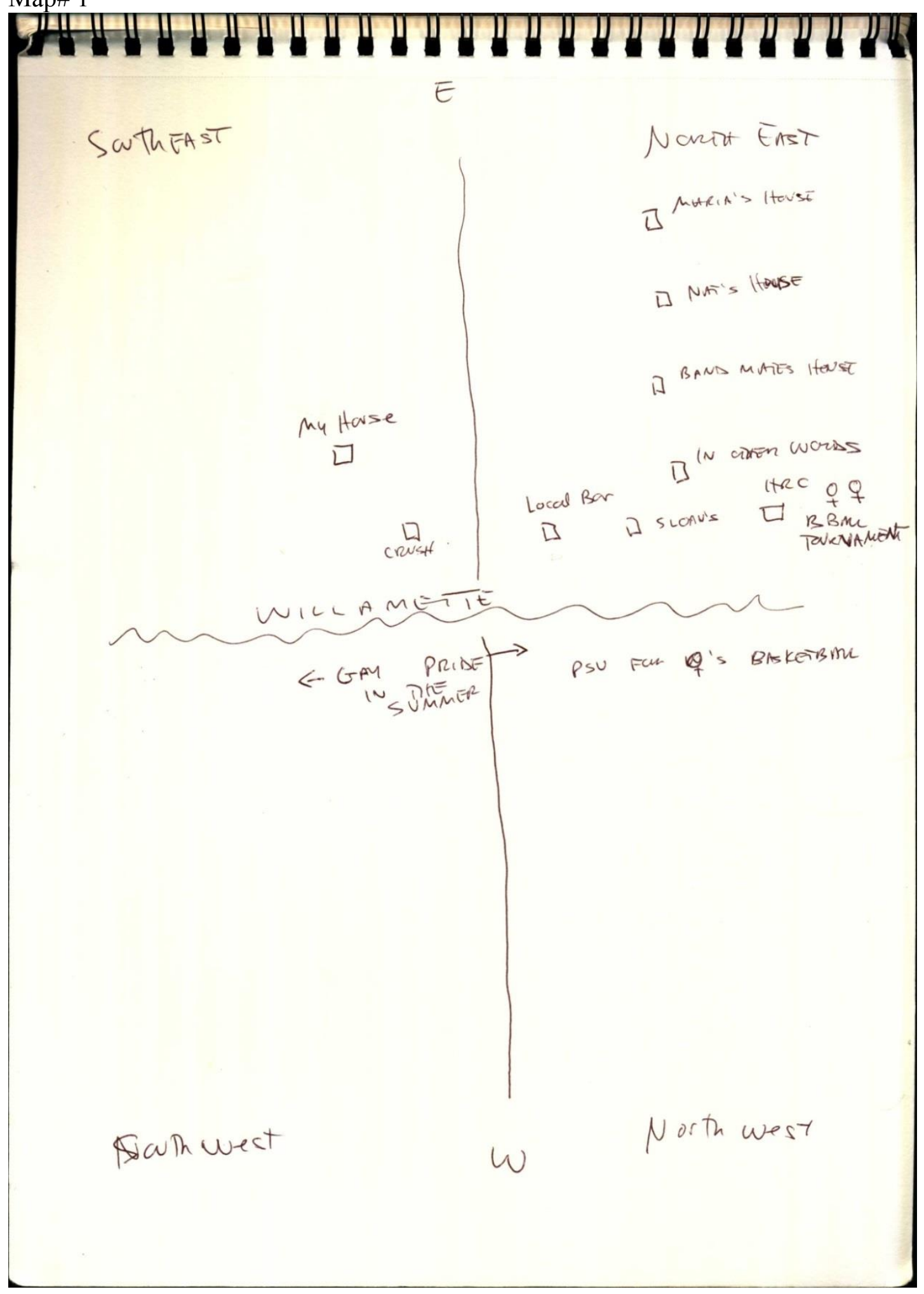




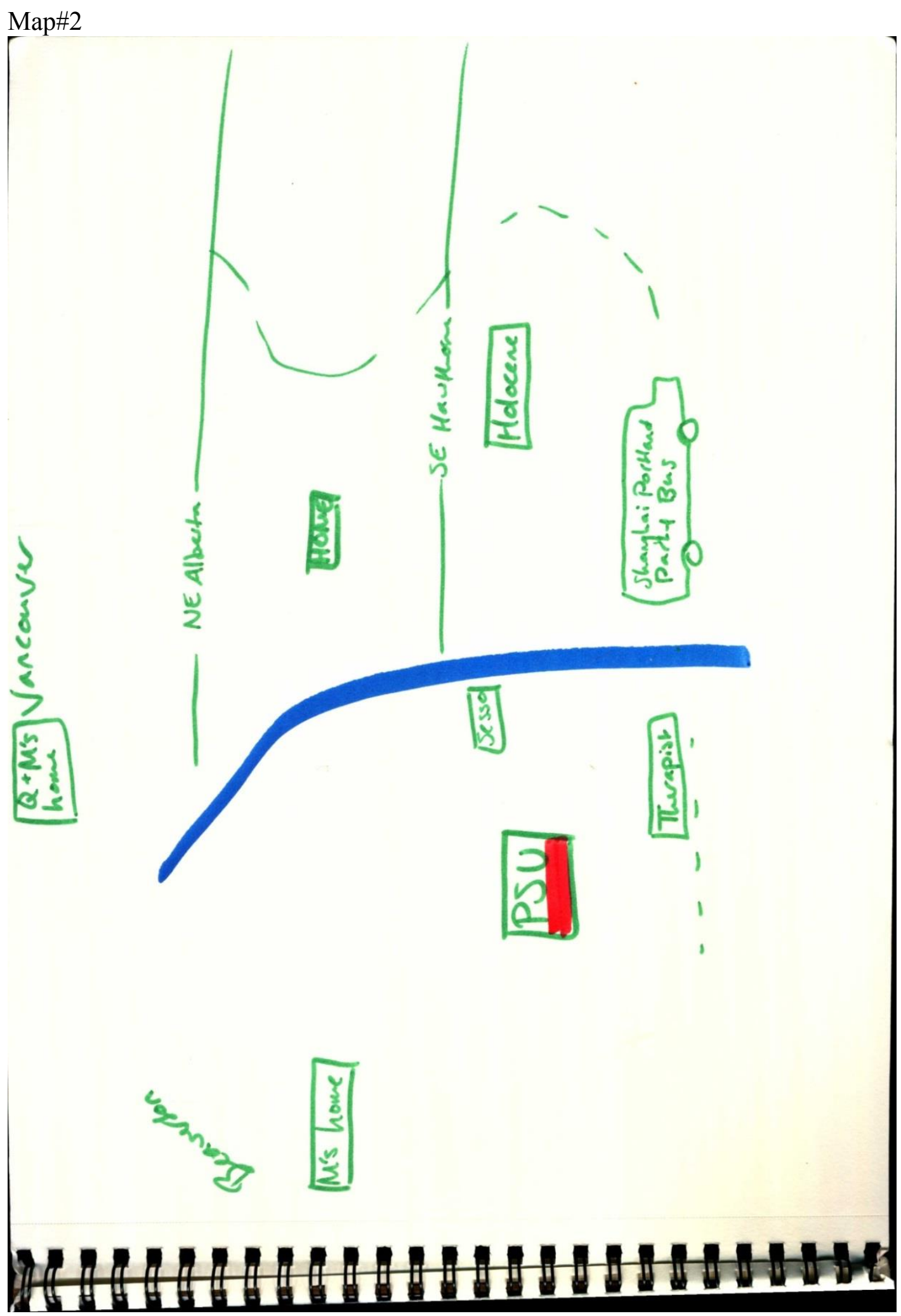




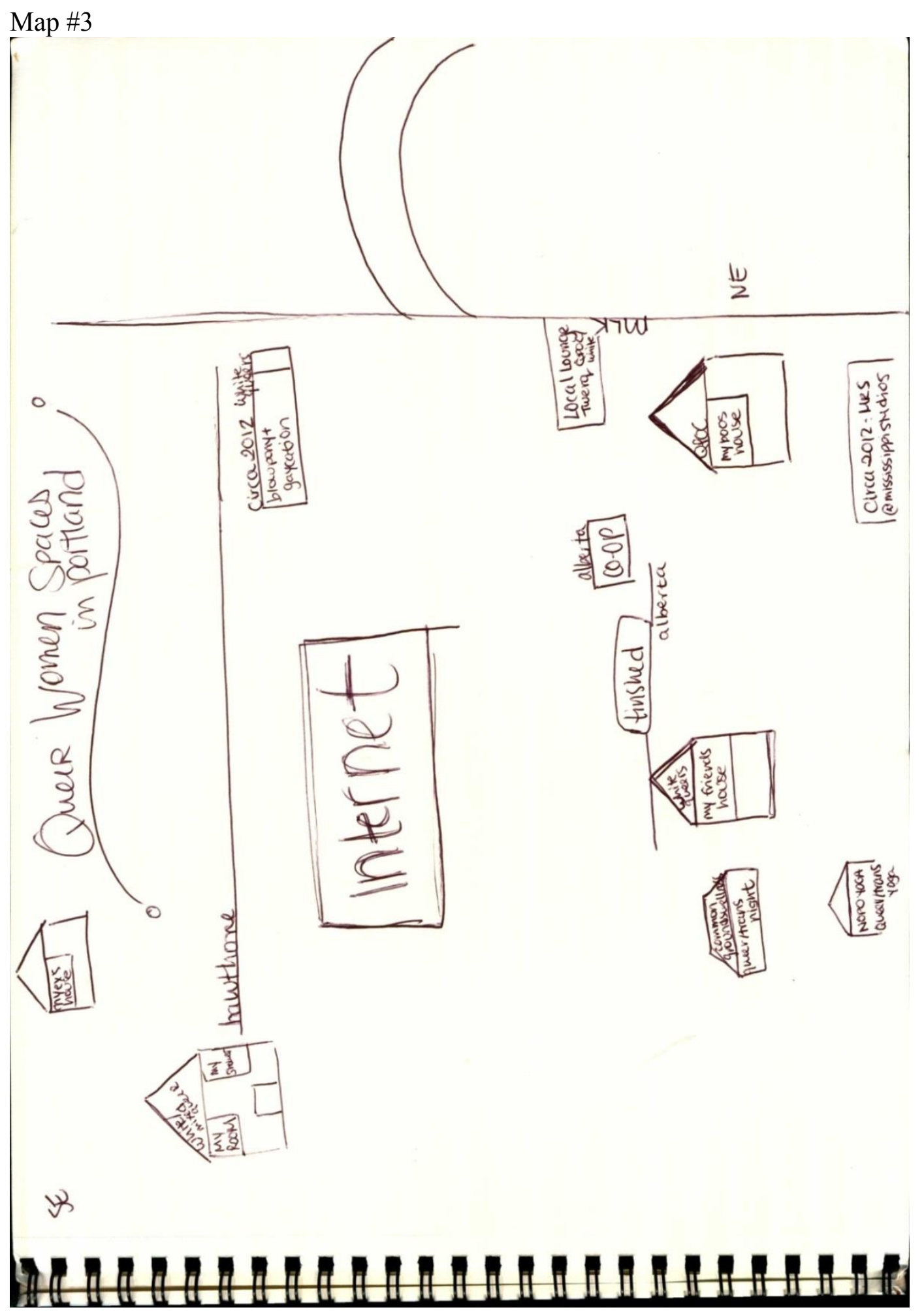


Map\#4

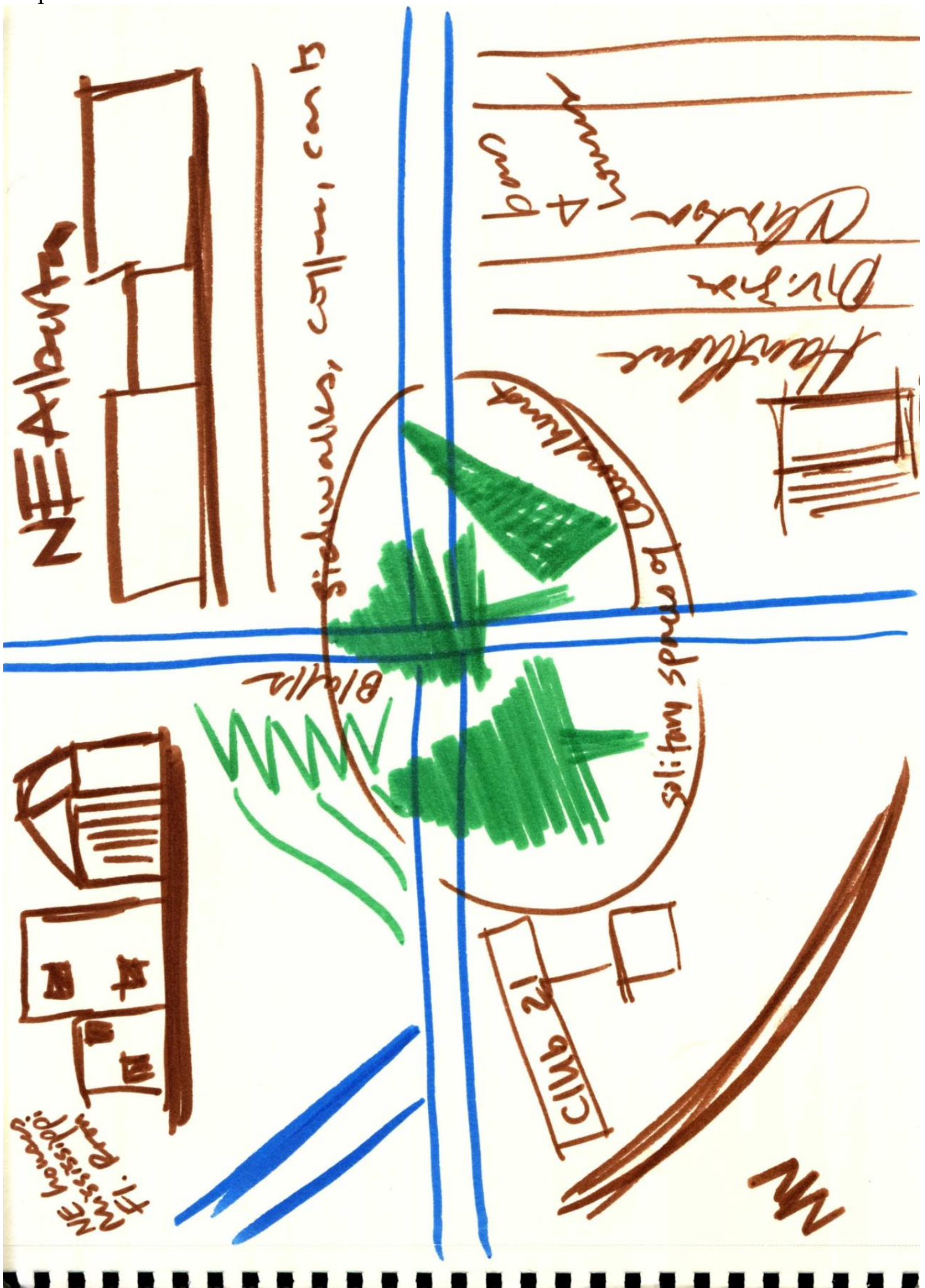


Map\#5

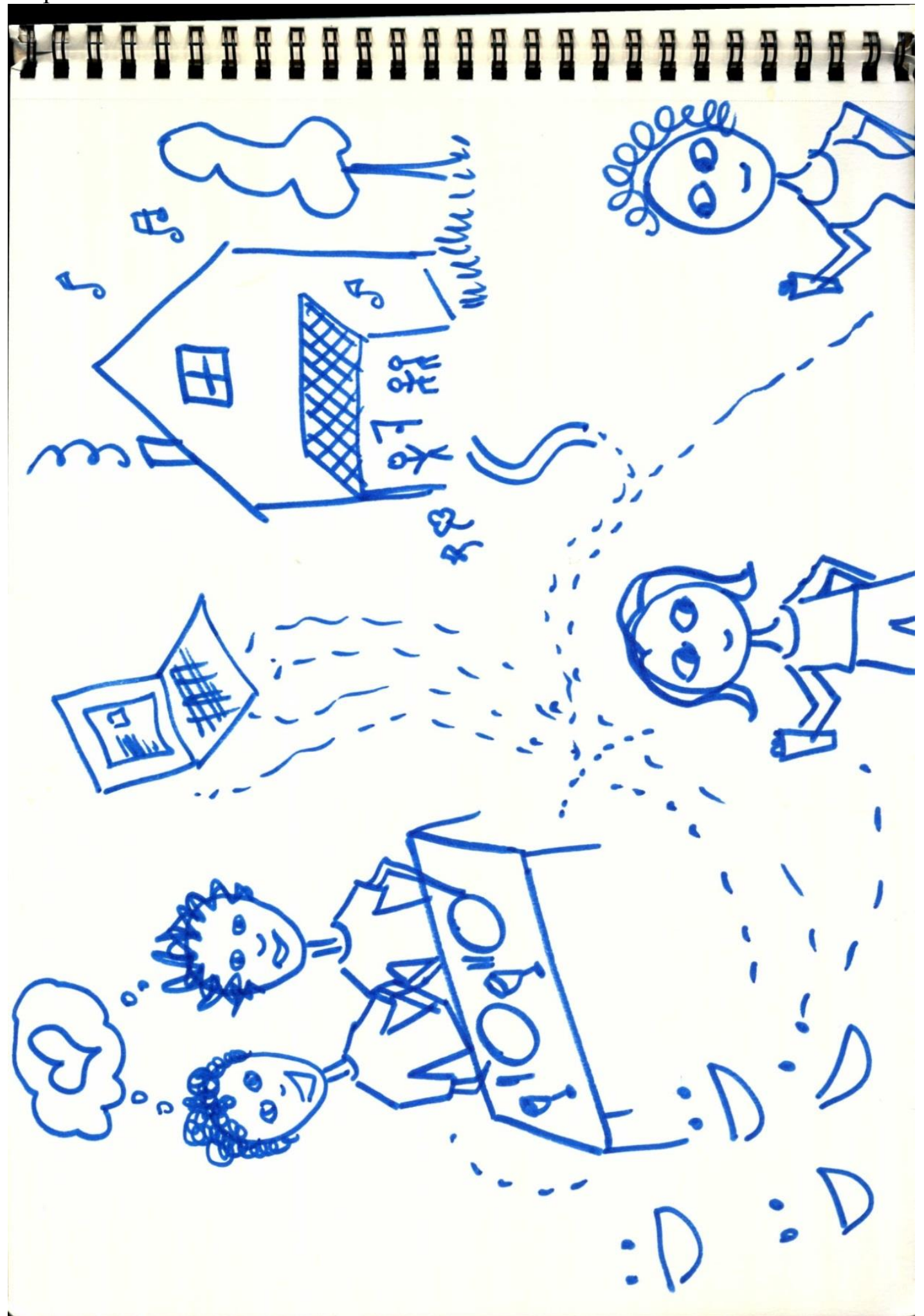




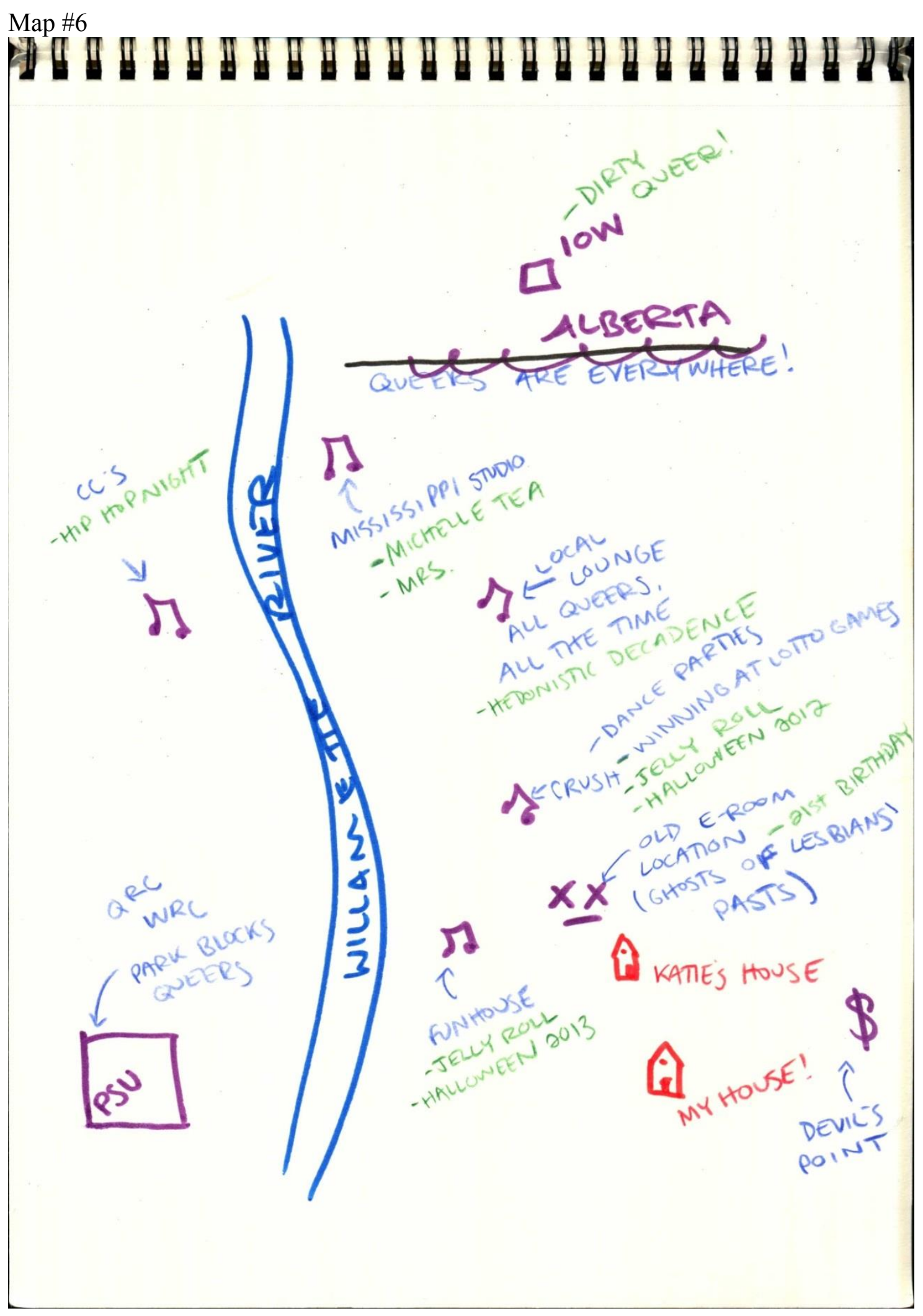


Map \#7 HTH.

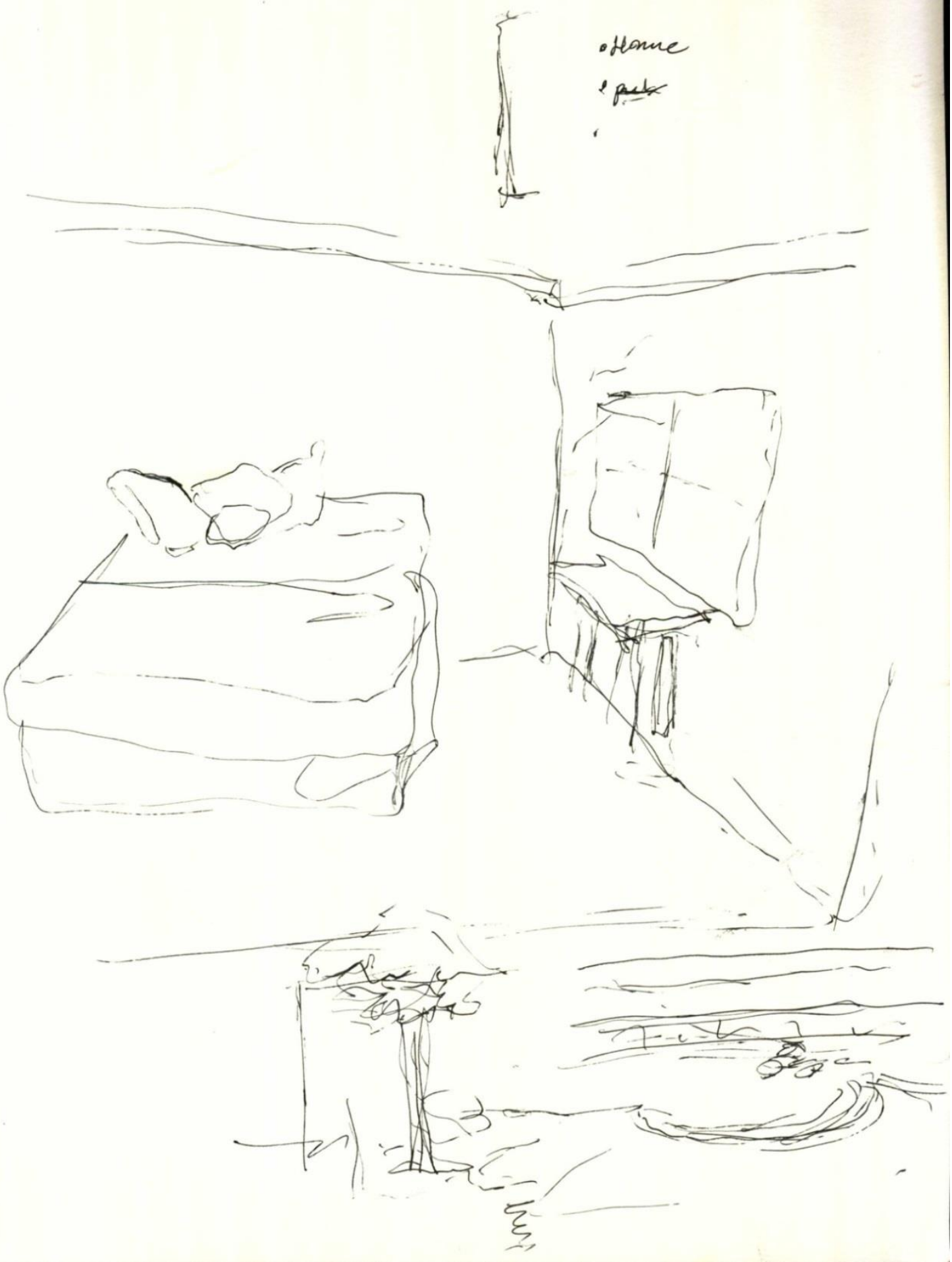




\section{Map \#8}

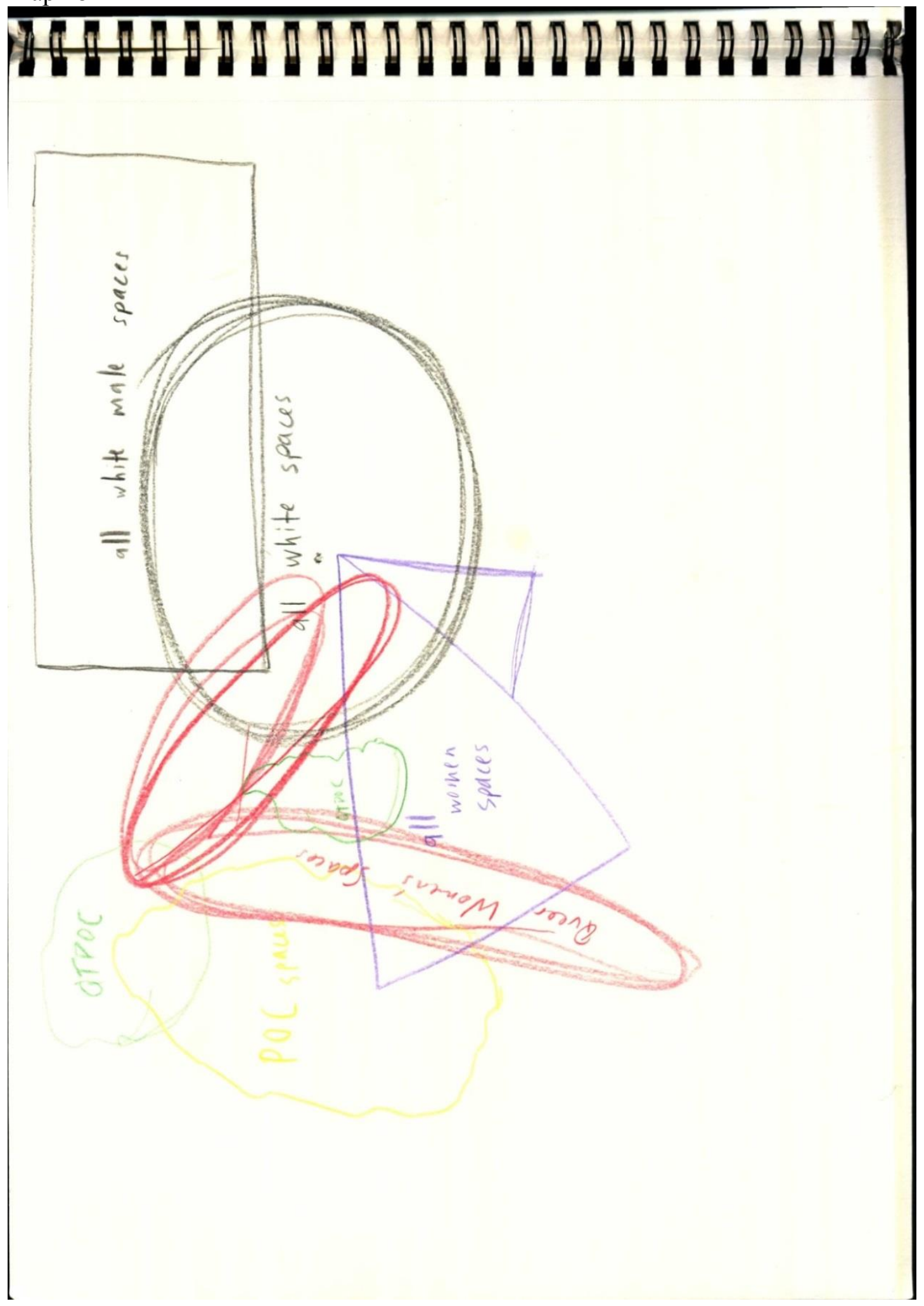




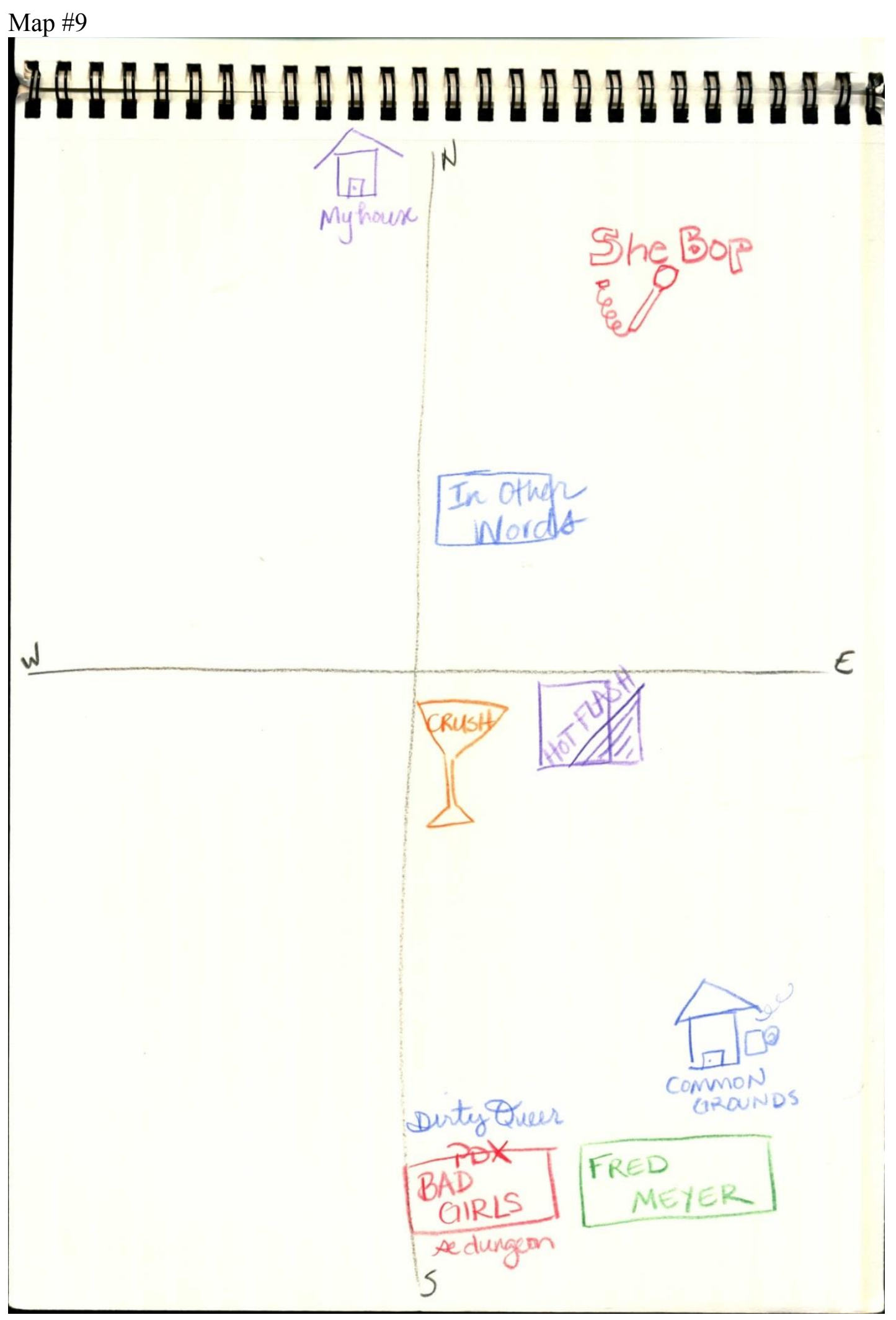


Map \#10

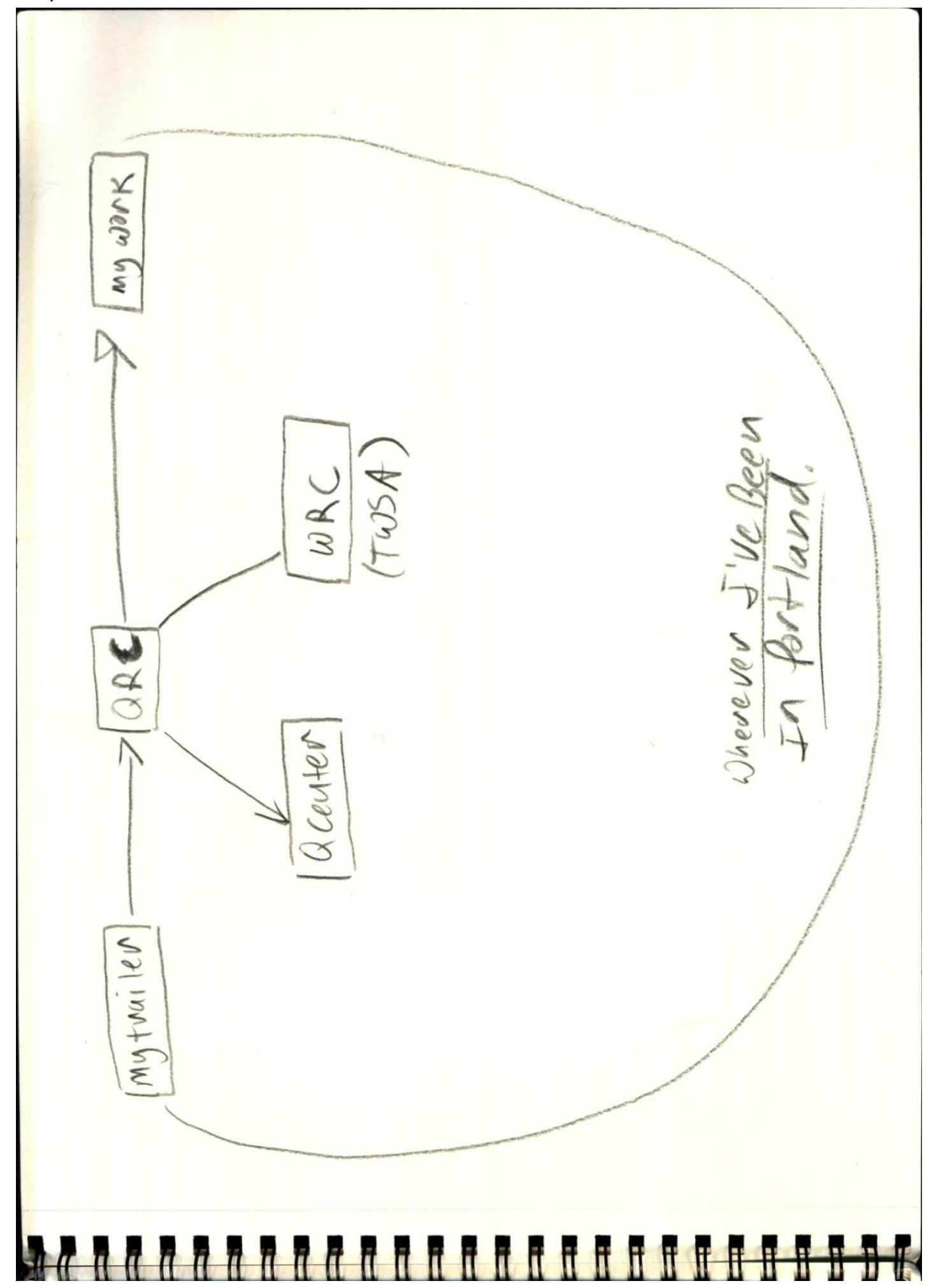


Map \#11

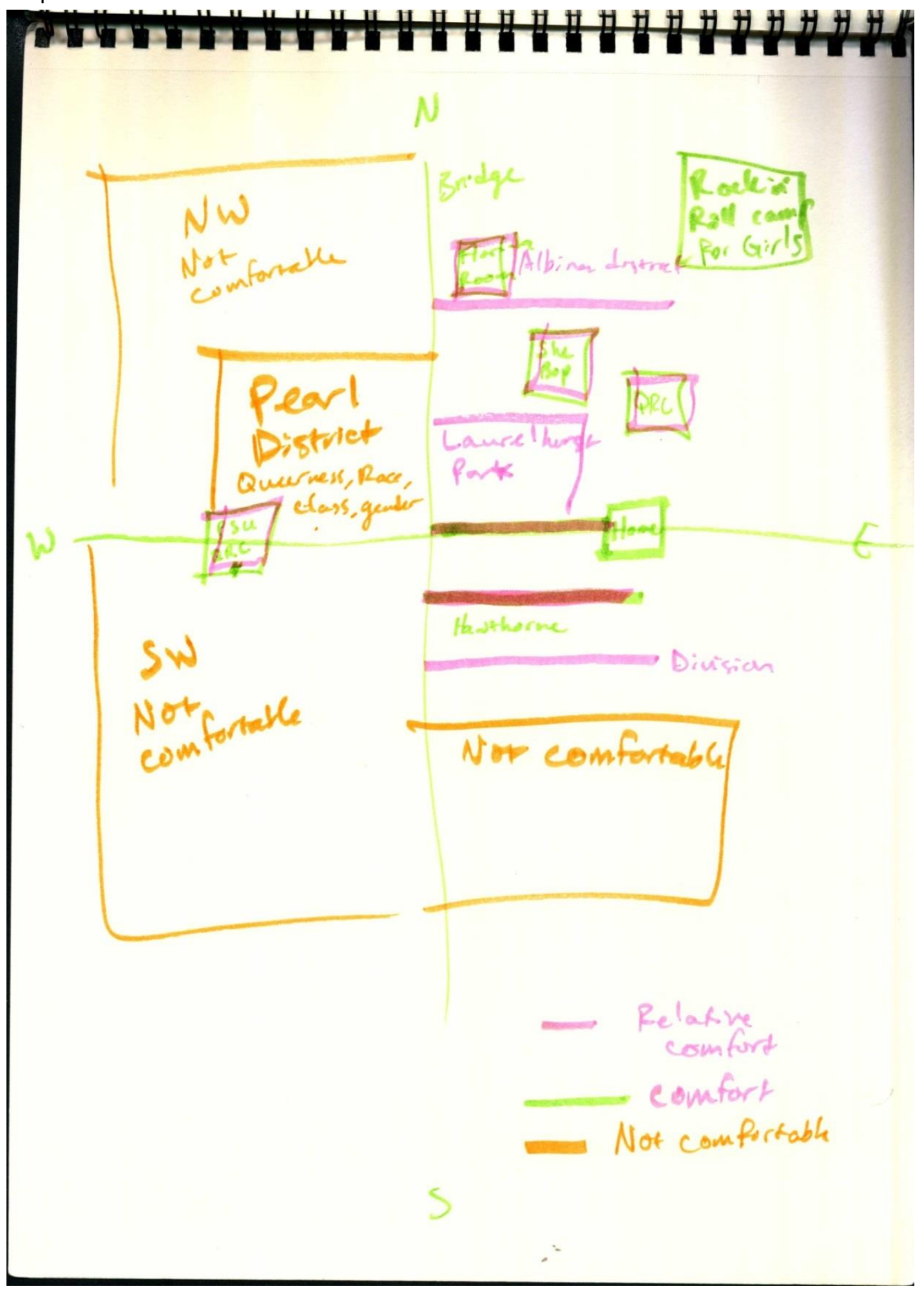


Map \#12

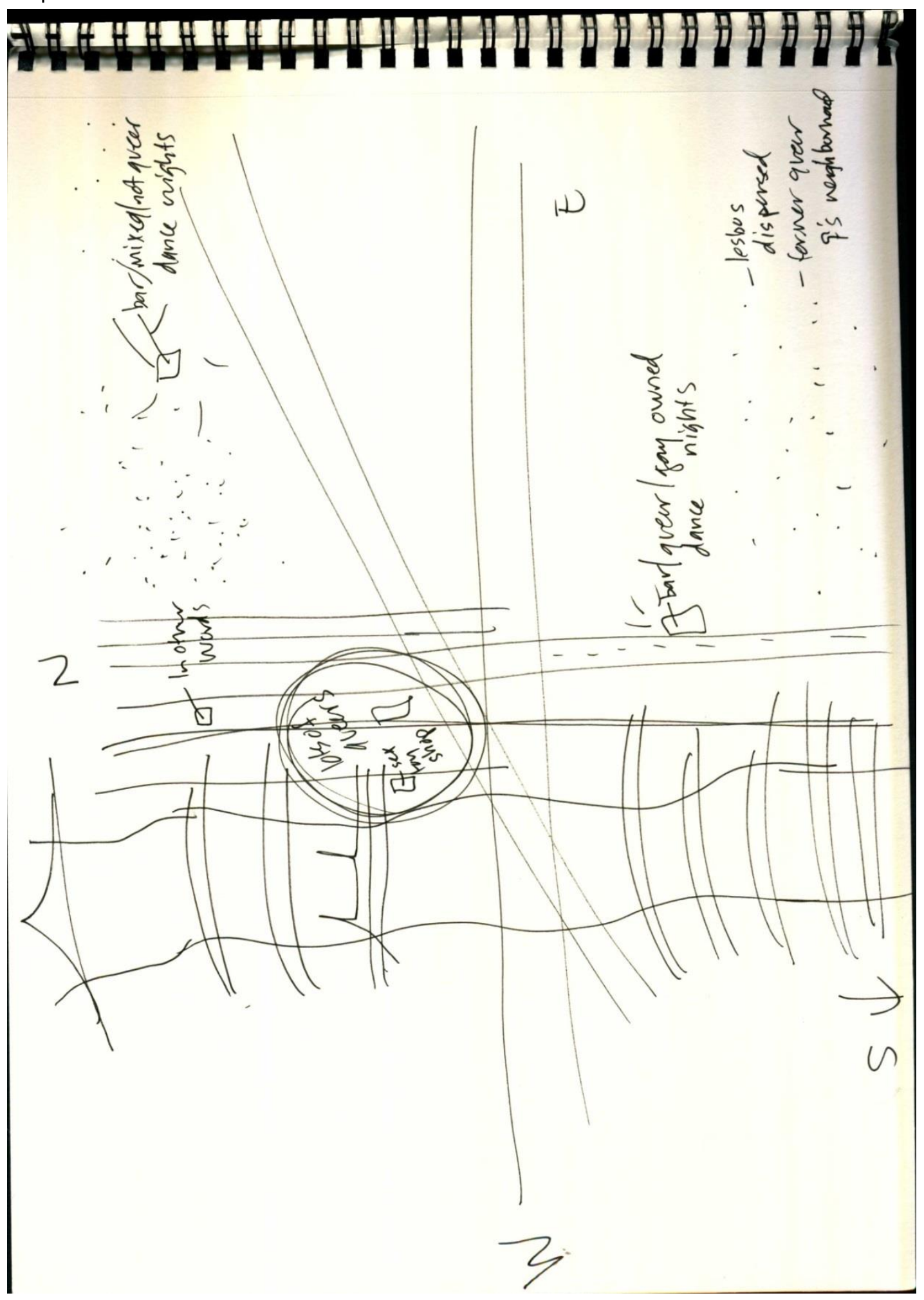


Map \#13

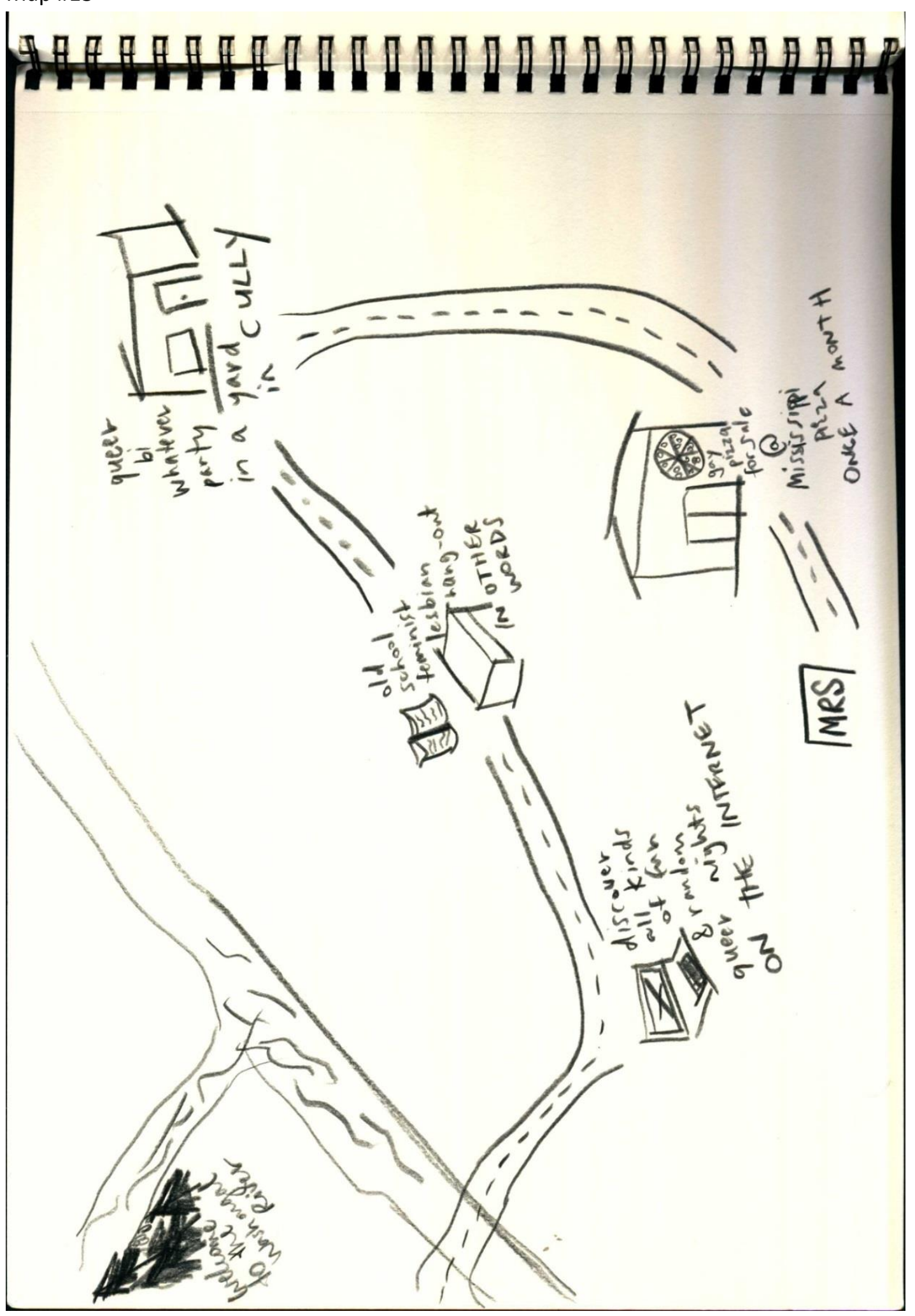




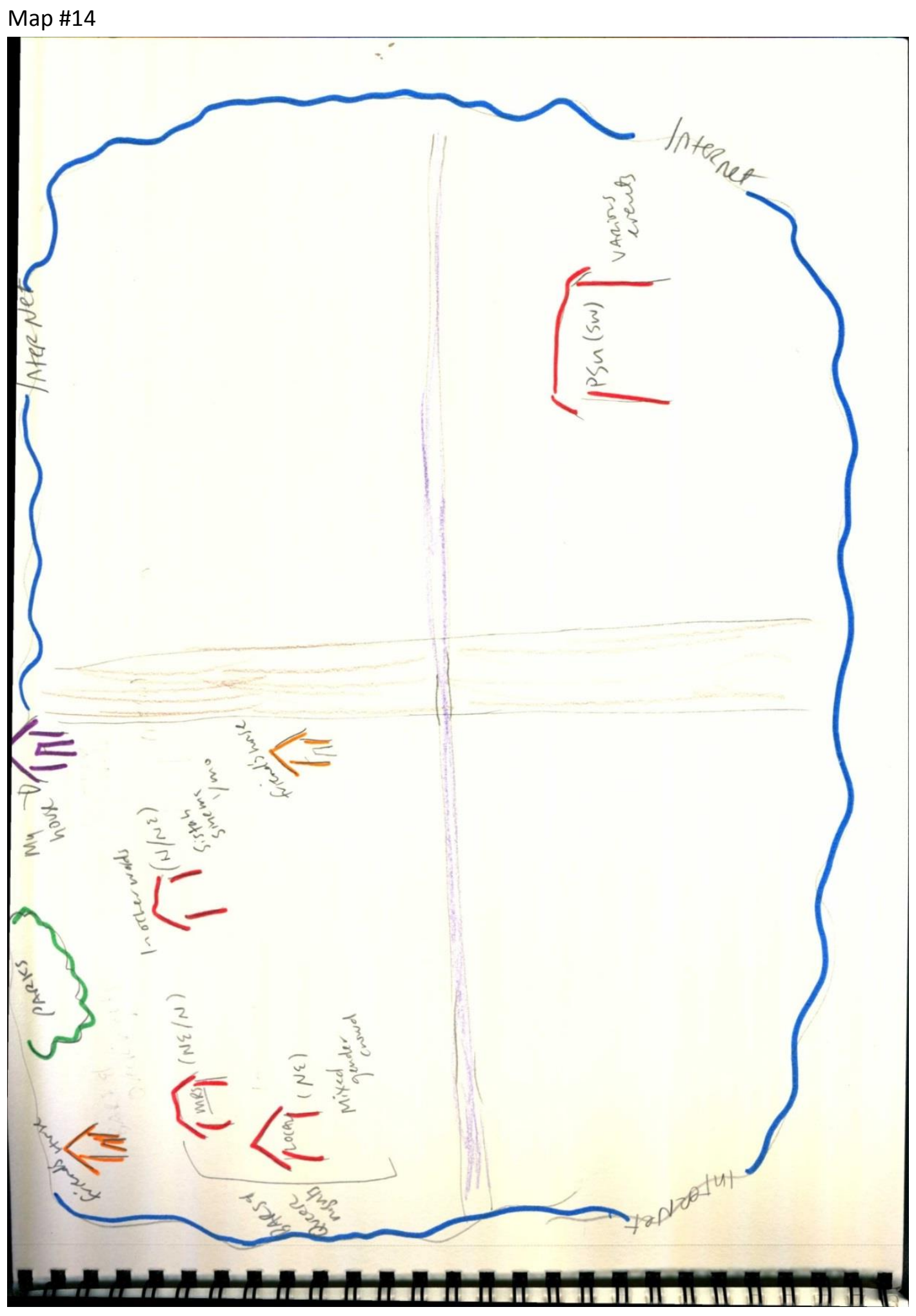


Map \#15

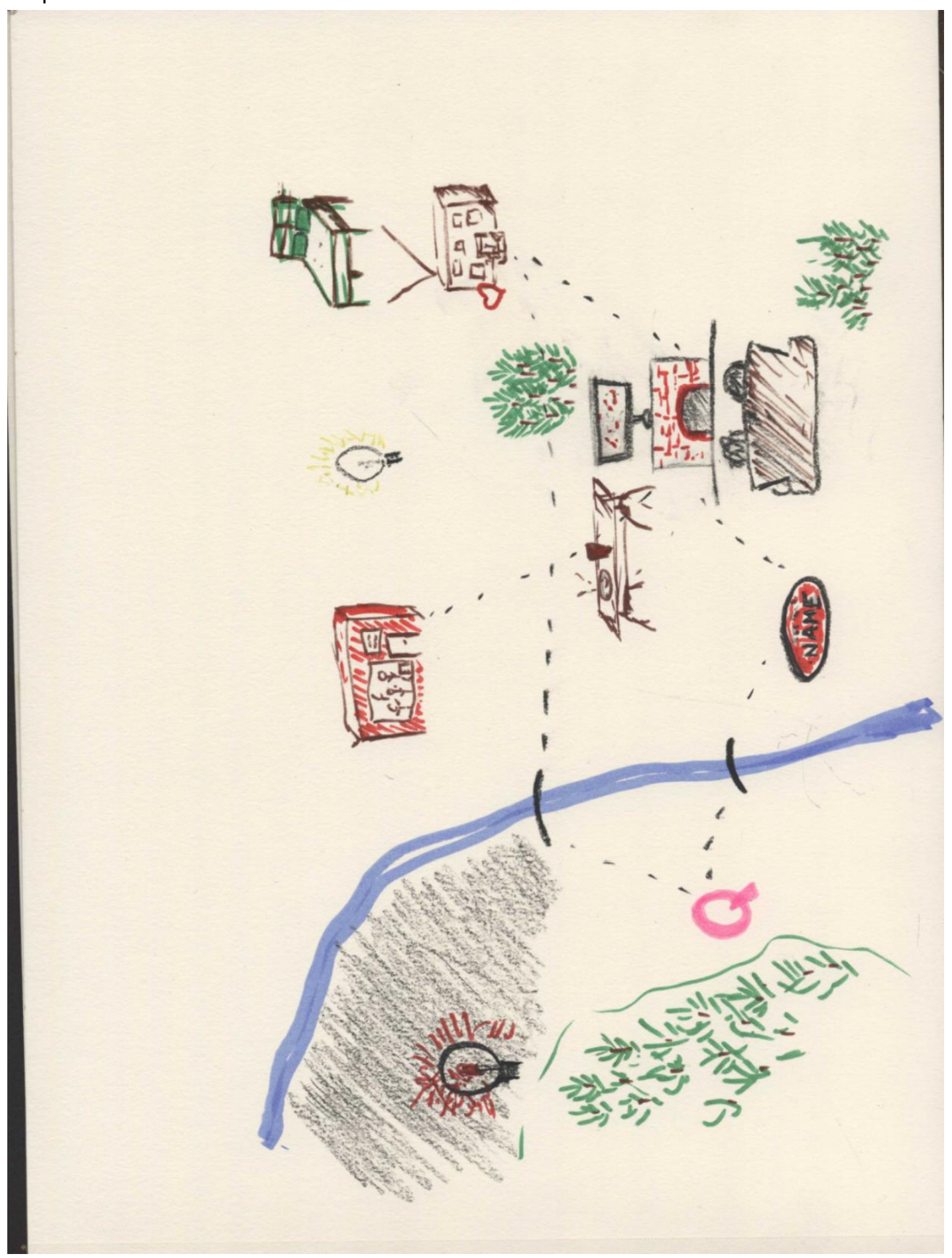

